\title{
Vulnerability of Oligodendroglia to Glutamate: Pharmacology, Mechanisms, and Prevention
}

\author{
Akira Oka, Michael J. Belliveau, Paul A. Rosenberg, and Joseph J. Volpe \\ Department of Neurology and Program in Neuroscience, Children's Hospital and Harvard Medical School, Boston, \\ Massachusetts 02115
}

Periventricular white matter injury, the principal variety of brain injury of the human premature infant, involves differentiating oligodendroglia. Nothing is known of the biochemical mechanism of oligodendroglial death in this disorder. Because an early event in periventricular white matter injury is ischemia-induced axonal disruption and because such axonal destruction could lead to a marked increase in local concentrations of glutamate, we evaluated the vulnerability of differentiating oligodendroglia to glutamate in a culture model. Oligodendroglia were isolated from mixed-glial primary cultures by a selective detachment technique and grown in a primary culture under conditions that lead to differentiation. These oligodendroglia were found to be highly vulnerable to glutamate-induced cell death. The $\mathrm{EC}_{50}$ for glutamate for a $24 \mathrm{hr}$ exposure was approximately $200 \mu \mathrm{M}$, comparable to the value reported for neurons in conventional cerebral cortical cultures. Astrocytes, in contrast, were shown to be resistant to as much as $5 \mathrm{~mm}$ glutamate. Study of glutamate receptor antagonists and glutamate transport substrates showed that the glutamate-induced oligodendroglial death was not related to a receptor mechanism, as operates in neurons, but rather was secondary to glutamate uptake by the oligodendroglia. Glutamate transport by highaffinity, sodium-dependent and by sodium-independent systems was shown. The central importance of glutamate uptake for the toxic effect of glutamate was shown by total prevention of the oligodendroglial toxicity by the simultaneous inhibition of glutamate uptake by the specific inhibitor $D, L-t h r e o-\beta$-hydroxyaspartate. Subsequent observations showed that the toxicity of glutamate was mediated by free radical attack, the consequence of glutathione depletion, apparently caused by the action of a glutamate-cystine exchange mechanism that results in cystine and thereby glutathione depletion. Thus, addition of cystine or cysteine totally prevented the glutamate toxicity to oligodendroglia. Second, glutamate exposure led to cystine efflux. Third, glutathione levels decreased markedly in cells exposed to glutamate, and this marked decrease preceded the loss of cell viability. Fourth, glutamate toxicity could be prevented totally by exposure to different free radical scavengers, vitamin $E$ and idebenone. The data thus show that glutamate is highly

\footnotetext{
Received Aug. 4, 1992; revised Sept. 25, 1992; accepted Oct. 5, 1992.

This investigation was supported by Grant R01-HD-07464 (to J.J.V.) from the National Institutes of Health. We acknowledge the expert technical assistance of Jerry Lin and Qi-Qi Mu.

Correspondence should be addressed to Joseph J. Volpe, M.D., Neurologist-inChief, Neurology Department, Fegan 1103, Children's Hospital, 300 Longwood Avenue, Boston, MA 02115.

Copyright $(C) 1993$ Society for Neuroscience $0270-6474 / 93 / 131441-13 \$ 05.00 / 0$
}

toxic to oligodendroglia. Moreover, the findings raise the possibilities that such glutamate toxicity is operative in the oligodendroglial cell death associated with ischemic processes that disrupt axons, such as periventricular white matter injury of the premature infant, and that novel therapies directed against glutamate transport, glutathione depletion, and free radical attack might be beneficial in prevention of that injury.

IKey words: glutamate toxicity, oligodendroglia, glutamate transport, glutathione depletion, free radicals, periventricular leukomalacia]

Oligodendroglia are an important cell type of the CNS and during development are responsible for the deposition of myelin (Bunge, 1968). This glial type is the chief cellular constituent of myelin, and as such, oligodendroglia play an important role in axonal conduction in the CNS. In addition, other functions suggested for oligodendroglia include the regulation of outgrowth (Schwab and Schnell, 1991) and regeneration of central neurons (Bastmeyer et al., 1991; Bray et al., 1991; Cadelli et al., 1992). Despite their obvious importance to the normal function of the brain, little is known about the cellular biology of these cells, although important recent studies have characterized the developmental sequence leading to their formation from multipotent precursors (Raff et al., 1983; Lopes-Cardozo et al., 1989; Gard and Pfeiffer, 1990; Knapp, 1991), as well as the presence of ion channels in their plasma membranes (Barres et al., 1988, 1990).

Oligodendroglia are involved in several important pathological states, including demyelination (Waxman, 1982), the hallmark of multiple sclerosis, white matter injury in stroke, and periventricular leukomalacia (Gilles and Murphy, 1969; Leviton and Gilles, 1971, 1973, 1974, 1984; Leviton et al., 1976; Dambska et al., 1989; Leviton and Paneth, 1990; Paneth et al., 1990), the principal neuropathology for the constellation of spastic motor and cognitive deficits that occurs in premature infants (Volpe, 1987, 1989). Experimental and clinical data indicate that periventricular leukomalacia is related to cerebral ischemia and is the consequence of at least three factors (Volpe, 1987, 1989), that is, the presence in the periventricular white matter of vascular border zones, the occurrence in the sick premature infant of a pressure passive cerebral circulation, and an intrinsic cellular factor. Concerning the cellular factor, experimental data show that hypoxic-ischemic lesions in white matter of developing animals are particularly likely to occur at sites of active myelination (Rice et al., 1981). That the oligodendroglial cell is the principal target in periventricular leukomalacia of the premature infant has been shown by the neuropathological findings of widespread loss of these cells in periventricular white 
matter (Dambska et al., 1989; Leviton and Paneth, 1990; Paneth et al., 1990) and by brain imaging findings of subsequently impaired myelination (Flodmark et al., 1989; van de Bor et al., 1989).

Significant progress has been made in understanding the cellular mechanisms underlying neuronal death in hypoxia-ischemia. The neuronal death that occurs in this setting appears to be due at least in considerable part to an accumulation of extracellular glutamate leading to excessive stimulation of glutamate receptors, in particular, the NMDA subtype of glutamate receptor (Choi et al., 1987; Choi, 1988; Choi and Rothman, 1990; Meldrum and Garthwaite, 1990). Little is known, however, about the specific cellular mechanisms underlying the death of oligodendroglia in the setting of hypoxia-ischemia in the developing brain. Because axonal disruption is among the earliest neuropathological features in periventricular leukomalacia (Banker and Larroche, 1962), we considered the possibility that glutamate released locally could be injurious to young oligodendroglia. In this study we show that oligodendroglia from developing rat brain in culture are very sensitive to glutamate toxicity. Further, we have characterized the pharmacology and mechanism of this toxicity.

\section{Materials and Methods}

Oligodendroglial and astrocyte cell culture. Mixed glial primary cultures were prepared by dissociation of brain obtained from 1-d-old SpragueDawley rats by a modification of earlier methods (Booher and Sensenbrenner, 1972; Hertz et al., 1982, 1985), as previously described (Langan and Volpe, 1986). Cells were maintained in Dulbecco's modified Eagle's medium (DME)/Ham's F-12 (1:1), with $1.2 \mathrm{gm} / \mathrm{liter}(14 \mathrm{mM})$ of $\mathrm{NaHCO}_{3}$ $15 \mathrm{~mm} N$-2-hydroxyethylpiperazine- $N$-2-ethanesulfonic acid (HEPES), and $10 \%$ fetal bovinc scrum, in $75 \mathrm{~cm}^{2}$ flasks in an atmosphere of $95 \%$ air and $5 \% \mathrm{CO}_{2}$ at $37^{\circ} \mathrm{C}$. After $7 \mathrm{~d}$ in culture, the flasks were shaken for $1 \mathrm{hr}$ on an orbital shaker $\left(37^{\circ} \mathrm{C}, 150 \mathrm{rpm}\right)$ to remove macrophages. The medium was discarded and replaced with $9 \mathrm{ml}$ of fresh medium. The flasks were then shaken for $15-18 \mathrm{hr}$ on an orbital shaker $\left(37^{\circ} \mathrm{C}, 210\right.$ $\mathrm{rpm}$ ). During the shaking process, phase-dark cells, which are principally oligodendroglial type 2 astrocyte $(\mathrm{O} 2 \mathrm{~A})$ progenitors (McCarthy and de Vellis, 1980; Bologa-Sandru et al., 1981; de Vellis et al., 1983; Eccleston and Silberberg, 1984), were detached from the bed layer of the phaselight, type 1 astrocytes (Mounen et al., 1975; Manthorpe et al., 1979; Raff et al., 1979; McCarthy and de Vellis, 1980; Sensenbrenner et al., 1980; Giulian and Baker, 1986).

For culture of oligodendroglia, we modified our previously published procedure (Ishii and Volpe, in press). The cell suspensions of the phasedark cells were combined, sedimented by centrifugation $(1500 \mathrm{rpm}$ for $10 \mathrm{~min}$ ), and suspended in a chemically defined medium (CDM) consisting of DME, $\mathrm{NaHCO}_{3}(3.7 \mathrm{gm} /$ liter, $44 \mathrm{~mm}), 15 \mathrm{~mm}$ HEPES, selenium $(5 \mu \mathrm{g} / 1)$, biotin $(2.4 \mu \mathrm{g} /$ liter $)$, triiodothyronine $(10 \mu \mathrm{g} /$ liter $)$, hydrocortisone (3.6 $\mu \mathrm{g} /$ liter), bovine serum albumin (fraction V) (1 gm/ liter), bovine insulin (5 mg/liter), pyruvate $(110 \mathrm{mg} /$ liter, $1 \mathrm{~mm})$, and human transferrin (iron poor) $(50 \mathrm{mg} / \mathrm{liter})$. The CDM was supplemented with $10 \%$ fetal bovine serum and astrocyte extract ( $10 \mu \mathrm{g}$ protein $/ \mathrm{ml}$ ) (Ishii and Volpe, in press). The suspension then was passed through a nylon mesh of $10 \mu \mathrm{m}$ pore diameter to remove any contamination by astrocytes and placed in an uncoated $75 \mathrm{~cm}^{2}$ flask for $10 \mathrm{~min}$ to remove any contamination by microglia (Giulian and Baker, 1986). Microglia adhere to the flask surface during this interval. The unattached cells then were seeded on poly-D-lysine-coated $35 \mathrm{~mm}$ culture dishes and 24-well plates (well diameter, $16 \mathrm{~mm}$ ) at a seeding density of 2.7 $\times 10^{4}$ cells $/ \mathrm{cm}^{2}$. For immunocytochemical staining, cells were seeded on poly-D-lysine-coated coverslips placed in $35 \mathrm{~mm}$ culture dishes. For autoradiography, cells were seeded on poly-D-lysine-coated culture slides. After the cells had attached to the surface, the medium was replaced with fresh medium in which the fetal bovine serum was replaced with boiled fetal bovine serum (Ishii and Volpe, in press).

For astrocyte cultures, cells of the bed layer of the mixed glial cultures remaining in the flasks after overnight shaking [95\% glial fibrillary acid protein (GFAP) positive] were incubated with a salt solution consisting of $140 \mathrm{~mm} \mathrm{NaCl}, 3.5 \mathrm{~mm}$ Tris- $\mathrm{HCl}(\mathrm{pH} 7.5)$, and $0.5 \mathrm{~mm}$ Tris base $(\mathrm{pH}$
7.5) supplemented with $0.6 \mathrm{~mm}$ EDTA for $30 \mathrm{~min}$ on an orbital shaker $(150 \mathrm{rpm})$ at $37^{\circ} \mathrm{C}$. Cell suspensions were centrifuged; resuspended in DME/F-12 (1:1), with $1.2 \mathrm{gm} /$ liter $\mathrm{NaHCO}_{3}, 15 \mathrm{~mm}$ HEPES, $10 \%$ fetal bovine serum; passed through a nylon mesh of $37 \mu \mathrm{m}$ pore diameter; and grown in poly-D-lysine-coated $35 \mathrm{~mm}$ culture dishes at a seeding density of $2.7 \times 10^{4}$ cells $/ \mathrm{cm}^{2}$.

Immunocytochemical staining. For staining of galactocerebroside (GC) or A2B5, procedures were essentially as previously described (Bansal et al., 1989; Gard and Pfeiffer, 1990). Briefly, nonspecific binding was blocked with 3\% goat serum in PBS for $20 \mathrm{~min}$. Cells were then labeled with monoclonal antibody (mAb) O1 (anti-GC) (1:20), or A2B5 antibody, as crude hybridoma culture medium (1:5) for $20 \mathrm{~min}$, followed by fluorescein isothiocyanate (FITC)-conjugated goat anti-mouse IgM (1:50) for $20 \mathrm{~min}$. All washes between steps were carried out on ice three times for 5 min each in PBS with $1 \%$ goat serum. For staining of GFAP, cells were fixed in cold 4\% paraformaldehyde in PBS for 20 min, permeabilized with $0.5 \%$ Triton $X-100$, and labeled with mouse monoclonal anti-GFAP $(1: 100)$ for $30 \mathrm{~min}$ at room temperature, followed by FITC-conjugated goat anti-mouse IgG $(1: 25)$ for $30 \mathrm{~min}$ at room temperature. Cells were visualized with interference filters for fluorescein detection.

Quantitation of viable cells. For the studies described in this report, oligodendroglial cultures grown for 3-5 d after separation from mixed glial cultures in CDM supplemented with $10 \%$ boiled fetal bovine serum and astrocyte extract $(10 \mu \mathrm{g}$ protein $/ \mathrm{ml})$ were utilized. For the studies of oligodendroglial toxicity, the medium was aspirated and replaced with Earle's balanced salt solution (EBSS) (containing $5.5 \mathrm{~mm}$ glucose). After additions to the flasks and incubations for the indicated times, oligodendrocyte viability was determined using a modification of the technique of Persidsky and Baillie (1977). Cells were incubated for 5 min with fluorescein diacetate (FDA) $(60 \mu \mathrm{g} / \mathrm{ml})$. The medium then was removed by aspiration and replaced with fresh EBSS. Cells were observed immediately, and fluorescein-labeled cells were identified by fluorescence microscopy. Cell counts were made in five adjacent fields at $200 \times$ magnification. Astrocytes, as determined by GFAP staining and by their distinct morphology, were excluded readily from cell counts of oligodendroglia. It should be noted that there was no evidence for loss of oligodendroglial viability in control cells maintained for as long as $48 \mathrm{hr}$ in EBSS when compared to cells maintained in complete growth medium.

${ }^{-5}{ }^{3} \mathrm{H}$-glutamate uptake. Glutamate uptake was determined in cells grown on 24-well plates. After the medium was aspirated from each dish, the adherent cells were washed once with $1 \mathrm{ml}$ of EBSS and given $0.3 \mathrm{ml}$ fresh salt solution containing $1.5-15.0 \mu \mathrm{Ci}$ of $\mathrm{L}-{ }^{3} \mathrm{H}$-glutamate $(49.0 \mathrm{Ci} / \mathrm{mmol})$ and indicated amounts of unlabeled $\mathrm{L}$-glutamate. The cells were incubated for the indicated times at $37^{\circ} \mathrm{C}$. After removal of medium, the cells were washed three times with ice-cold PBS and then lysed with $0.1 \mathrm{~N} \mathrm{NaOH}$. Protein concentration was determined in an aliquot of lysate by the method of Bradford (1976). The lysate was neutralized with $\mathrm{HCl}$ and radioactivity determined by liquid scintillation spectroscopy. Counting efficiency was approximately $30 \%$. In experiments investigating the ion dependency of transport, EBSS was replaced with Tris-buffered saline (TBS) consisting of $120 \mathrm{mM} \mathrm{Na}{ }^{+}, 5.4$ mM K', $130.6 \mathrm{mM} \mathrm{Cl}^{-}, 1.8 \mathrm{mM} \mathrm{Ca}^{2+}, 0.8 \mathrm{mM} \mathrm{Mg}^{2+}, 16 \mathrm{~mm}$ glucose, and $25 \mathrm{~mm}$ Tris base. Sodium and chloride were replaced in isomolar amounts by $N$-methylglucamine and sulfate, respectively.

$L^{-3} \mathrm{H}$-glutamate autoradiography. Autoradiography was performed by a modification of the method of Murphy et al. (1990). After the medium was aspirated from each culture slide, the adherent cells were washed once with $2 \mathrm{ml}$ of EBSS and given $1.5 \mathrm{ml}$ of fresh EBSS containing $L^{-}{ }^{3} \mathrm{H}$-glutamate $(1.7 \mu \mathrm{Ci} / \mathrm{ml}$; final glutamate concentration, $33 \mathrm{nM})$. The cells were incubated for $5 \mathrm{~min}$, washed three times in ice-cold PBS, fixed in $2.5 \%$ glutaraldehyde $(0.2 \mathrm{~m}$ phosphate buffer, $\mathrm{pH} 7.0)$ for 30 min at room temperature, washed once with distilled water, air dried, dipped in Kodak NTB2 photographic emulsion, exposed for 12-14 d, and then developed with Kodak Dektol developer.

Glutathione measurement. Glutathione concentration was determined using a modification of the method described by Murphy et al. (1989). Cells were grown on $35 \mathrm{~mm}$ culture dishes for 3-5 d as described above. The medium was aspirated and the cells were washed once with EBSS. Two milliliters of $3 \%$ perchloric acid were added to each dish and allowed to incubate for $15 \mathrm{~min}$ on ice. The supernatant solution was transferred to a test tube containing $0.6 \mathrm{ml}$ of $3 \mathrm{M}$ potassium bicarbonate. The cells, still attached to the culture dishes, were harvested for protein determination as described below. For determination of glutathione, $0.3 \mathrm{ml}$ of the supernatant solution was placed into a $1 \mathrm{ml}$ 
cuvette with the following: $0.1 \mathrm{ml}$ of DTNB $\left(5,5^{\prime}\right.$-dithio-bis [2-nitrobenzoic acid], $2.4 \mathrm{mg} / \mathrm{ml}), 0.1 \mathrm{ml}$ of glutathione reductase $(10.5 \mathrm{U} / \mathrm{ml})$, $0.1 \mathrm{ml}$ of NADPH $(1.7 \mathrm{mg} / \mathrm{ml}), 0.4 \mathrm{ml}$ of $0.1 \mathrm{M}$ phosphate buffer with 5 mM EGTA ( $\mathrm{pH}$ 7.5). The change of $\mathrm{A}_{412}$ was determined spectrophotometrically. Measurements were compared to glutathione standards treated identically. The protein was extracted by sonication in $2 \mathrm{ml}$ of $20 \mathrm{~mm}$ Tris buffer, $1 \%$ SDS (pH 7.4). Protein was determined by the method of Lowry (1951).

Efflux of [ ${ }^{35} S$ ] radioactivity. Cells grown in $35 \mathrm{~mm}$ dishes were washed once with EBSS and incubated in EBSS containing $1.5 \mu \mathrm{Ci}$ of $\mathrm{L}^{-35} \mathrm{~S}$ cystine $(405.2 \mathrm{Ci} / \mathrm{mmol})$ for $60 \mathrm{~min}$. After washing three times in EBSS with $0.6 \%$ BSA, cells were incubated in $1.2 \mathrm{ml}$ of EBSS with 0 or $2 \mathrm{mM}$ L-glutamate for the indicated timcs at $37^{\circ} \mathrm{C}$ on a rotary shaker $(25 \mathrm{rpm})$. After incubation, media were collected, and cells were washed once and lysed in $0.1 \mathrm{~N} \mathrm{NaOH}$. Radioactivity in media and cells were determined by liquid scintillation spectroscopy, and aliquots were immediately frozen at $-80^{\circ} \mathrm{C}$ for chromatography. Counting efficiency was approximately $90 \%$. Percentage of efflux of $\left[{ }^{35} \mathrm{~S}\right]$ radioactivity was defined as follows:

$$
\% \text { efflux of }\left[{ }^{35} \mathrm{~S}\right] \text { radioactivity }=\frac{\left[{ }^{35} \mathrm{~S} \text { in medium }\right]}{\left[{ }^{35} \mathrm{~S} \text { in cells }\right]+\left[{ }^{35} \mathrm{~S} \text { in medium }\right]} \times 100 .
$$

Chromatographic analysis of effluxed $\left[{ }^{35} S\right]$ radioactivity. Thin-layer chromatographic analysis was performed using a modification of States and Segal (1969). A $30 \mu \mathrm{l}$ aliquot of medium derived from the efflux experiments described above was combined with $1.5 \mu \mathrm{g}$ of cystine, 1.5 $\mu \mathrm{g}$ of cysteine, $1 \mu \mathrm{g}$ of oxidized glutathione, $4 \mu \mathrm{g}$ of reduced glutathione, and $3 \mu \mathrm{g}$ of $N$-ethylmaleimide and analyzed by thin-layer chromatography on cellulose, using an isopropanol:methyl ethyl ketone: $1 \mathrm{~N} \mathrm{HCl}$ (3:2:3) solvent system. After detection by ninhydrin, spots were cut out and radioactivity determined by liquid scintillation spectroscopy.

Materials. Tissue culture media (DME, DME/F-12) and HEPES were purchased from GIBCO; Earle's balanced salt solution, D,L-threo- $\beta$ hydroxyaspartic acid (BHA), L-glutamate, D-glutamate, L-aspartate, D-aspartate, L-cystine, L-cysteine, NMDA, kainic acid, CDM constituents, glutaraldehyde, GFAP antibody, vitamin E, and FDA, from Sigma; FITC-conjugated goat anti-mouse IgG and IgM, from Vector Laboratories; A2B5 hybridoma clone, from American Type Culture Collection; fetal bovine serum, from Hyclone; 6-cyano-7-nitroquinoxaline-2,3-dione (CNQX), from Cambridge Research; MK-801, from Research Biochemicals, Inc.; L- ${ }^{3} \mathrm{H}$-glutamate and $\mathrm{L}^{3}{ }^{35} \mathrm{~S}$-cystine, from New England Nuclear; cellulose chromatography sheets and photographic materials, from Kodak; nylon mesh, from Small Parts; $35 \mathrm{~mm}$ culture dishes, 24well plates, and $75 \mathrm{~cm}^{2}$ culture flasks, from Falcon; culture slides, from Nunc; and Sprague-Dawley rats, from Charles River Laboratories. Idebenone was kindly donated by Takeda Chemical Co. (Osaka, Japan), and anti-GC monoclonal antibody, by Dr. Stephen Pfeiffer, University of Connecticut. All other chemicals were purchased from standard sources.

\section{Results}

Immunocytochemical characterization of oligodendroglial cultures. We determined the immunocytochemical characteristics of the cells obtained with our newly modified procedure for culturing oligodendroglia (see Materials and Methods). One day after plating, the cultures consisted of $86 \%( \pm 4 \% \mathrm{SD}, n=8)$ A2B5-positive cells, presumed O2A progenitors, $7 \%( \pm 3 \% \mathrm{SD}$, $n=7$ ) GC-positive oligodendroglia, and 4\% GFAP-positive astrocytes (Fig. 1). The remaining 3\% of cells were not stained by either of these two antibodies or by antibody to GFAP. On the third day, the cultures contained $81 \%( \pm 4 \% \mathrm{SD}, n=11)$ GC-positive oligodendroglia (Fig. 1), with only 10\% A2B5-positive cells. Cells expressing GC on the surface displayed relatively small round soma and complex branched processes, whereas A2B5-positive presumed progenitors were small, phasedark cells with one or two short processes and lacking the complcx branched processes. These morphologies were entirely consistent with previously reported observations (McMorris and Dubois-Dalcq, 1988; Gard and Pfeiffer, 1990; Ishii and Volpe, in press). Astrocytes, as determined by GFAP staining, account- ed for $4 \%$ of the cells on the third day after plating. These cells were flat, polygonal shaped, sometimes with long single processes. Astrocytes were morphologically easily distinguishable from oligodendroglia and presumed progenitors. Moreover, oligodendroglia were easily distinguishable from presumed progenitors. After $4-5 \mathrm{~d}$ of subculture, approximately $88 \%( \pm 4 \%$ $\mathrm{SD}, n=7$ ) of the cells were GC positive, with $8 \% \mathrm{~A} 2 \mathrm{~B} 5$ positive $( \pm 2 \% \mathrm{SD}, n=9)$ and $4 \%$ GFAP positive (Fig. 1). All of the experiments described below employed cells at this stage in culture.

Toxicity of glutamate to oligodendroglia and to astrocytes. To evaluate whether glutamate might be involved in mediation of oligodendroglial cell death, we initially asked whether glutamate exhibited toxicity in purified preparations of oligodendroglia. We found that cultures of purified oligodendroglia were destroyed essentially entirely by a $24 \mathrm{hr}$ exposure to $2 \mathrm{~mm}$ glutamate (see next section). To determine the concentration dependence of the toxic effect of glutamate on oligodendroglia, we exposed cultures to graded concentrations of glutamate for 24 $\mathrm{hr}$, at which time the numbers of viable cells were determined by the FDA method (Fig. 2). In parallel experiments, we exposed cultures of astrocytes to similar concentrations of glutamate (Fig. 2). Glutamate was found not to be toxic to astrocytes, even at concentrations as high as $5 \mathrm{~mm}$. However, glutamate led to oligodendroglial cell death at concentrations in the micromolar range. The $\mathrm{EC}_{50}$ in the experiment depicted in Figure 2 was 132 $\mu \mathrm{M}$, a value that is similar to that observed with rat or mousc neurons in conventional cerebral cortical cultures (Koh and Choi, 1988; Rosenberg and Aizenman, 1989).

Time course of glutamate toxicity to oligodendroglia. We next evaluated the temporal characteristics of the toxic effect of glutamate on oligodendroglia (Figs. 3, 4). Control cultures incubated in EBSS with no L-glutamate for $24 \mathrm{hr}$ were undamaged (Fig. $3 A$ ). After $12 \mathrm{hr}$ approximately $50 \%$ of cells exhibited membrane disintegration (Fig. $3 B$ ) and loss of viability by the FDA method (Fig. 4). By $24 \mathrm{hr}$ essentially all cells had disintegrated (Fig. $3 \mathrm{C}$ ) and lost viability (Fig. 4)

Pharmacology of glutamate toxicity to oligodendroglia. Because the toxicity of glutamate to cultured central neurons appears to occur primarily because of activation of excitatory amino acid receptors (for reviews, see Choi, 1988; Choi and Rothman, 1990; McDonald and Johnston, 1990), we next determined whether similar receptor-mediated mechanisms might underlie the glutamate toxicity to oligodendroglia. We found that the toxicity of $2 \mathrm{~mm}$ glutamate could not be blocked by 20 $\mu \mathrm{M}$ MK-801, an uncompetitive antagonist of the NMDA receptor (Wong et al., 1986; Huettner and Bean, 1988) (Fig. 5). CNQX, a competitive antagonist of non-NMDA receptors (Honore et al., 1988; Watkins et al., 1990), had no effect on glutamate toxicity to oligodendroglia up to concentrations of 200 $\mu$ M (Fig. 5). Similarly, $20 \mu$ M MK-801 plus $200 \mu$ M CNQX, a combination that has been shown to block swelling in neurons (Koh and Choi, 1991), had no effect on glutamate toxicity to oligodendroglia (data not shown).

Effect of glutamate transport substrates on oligodendroglia. Because activation of glutamate receptors did not seem to be required for toxicity, we next examined the possibility that the toxicity of glutamate was a transport-dependent process. Thus, we evaluated the oligodendroglial toxicity of several compounds with different affinities for the glutamate uptake system (Table 1). The $\mathrm{EC}_{50}$ values for the four compounds ranged from the lowest of $24 \pm 12 \mu \mathrm{M}$ for D-aspartate to the highest of $1107 \pm$ 

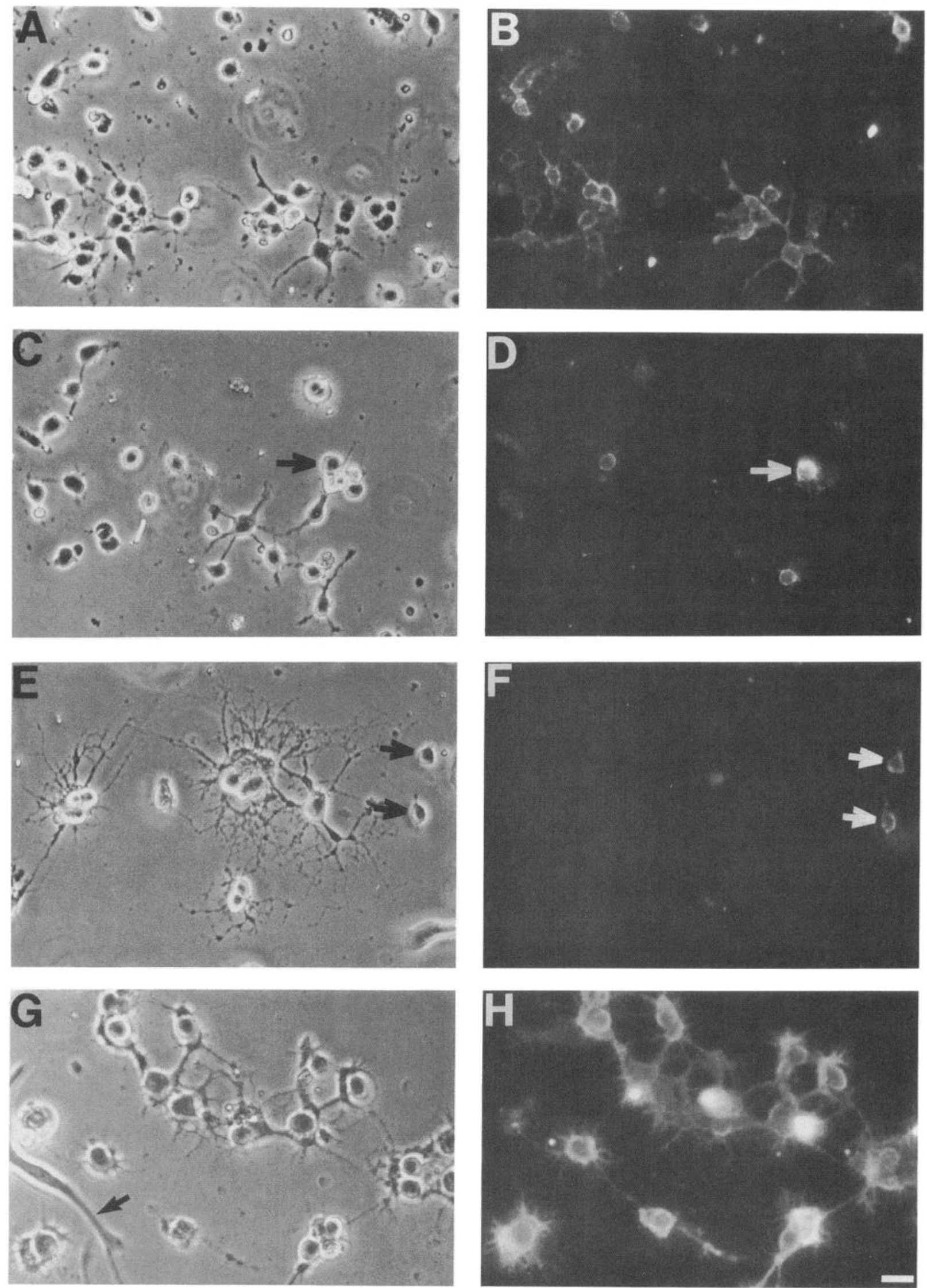

Figure 1. Oligodendroglial cultures. Cells separated from mixed glial primary cultures derived from rat cerebral hemispheres (see Materials and Methods) were maintained in CDM supplemented with boiled fetal bovine serum and astrocyte extract for $1 \mathrm{~d}(A-D)$ or $4 \mathrm{~d}(E-H)$. Cells were labeled with A2B5 antibody $(B, F)$ or $\mathrm{mAb}$ Ol (anti-GC antibody; $D, H)$ followed by FITC-conjugated second antibody (see Materials and Methods). 


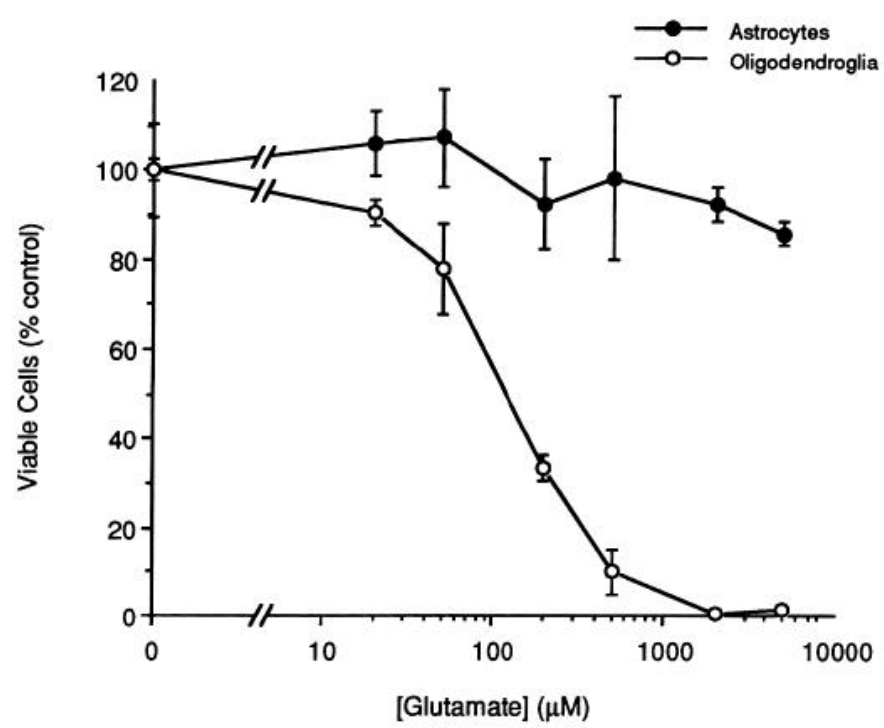

Figure 2. L-Glutamate is toxic to oligodendroglia but not to astrocytes. Oligodendroglial and astroglial subcultures were exposed to L-glutamate in EBSS for $24 \mathrm{hr}$, and viable cells, stained with FDA, were counted as described in Materials and Methods. Oligodendroglia (open circles) were highly vulnerable to L-glutamate $\left(\mathrm{EC}_{50}, 132 \mu \mathrm{M}\right)$. No significant toxicity was observed in astrocytes (solid circles) up to $5 \mathrm{~mm}$ of L-glutamate. Data are presented as the percentage of viable cells compared to control cultures (incubated in EBSS without L-glutamate). The number of viable oligodendroglia and astrocytes in control cultures was 332 and 153, respectively. Values represent the mean \pm SD in an experiment performed in triplicate. Similar results were obtained in three other experiments.

$34 \mu \mathrm{M}$ for L-aspartate. L- and D-glutamate had similar values for the $\mathrm{EC}_{50}$, that is, $197 \pm 29 \mu \mathrm{M}$ and $174 \pm 86 \mu \mathrm{M}$, respectively. L-Glutamate, L-aspartate, and D-aspartate in astrocytes and neurons are all transported by a sodium-dependent high-affinity transport system (see later discussion). However, the toxicity of D-glutamate suggests the involvement of a low-affinity transport system, recognized in a variety of neural and non-neural cells (see later discussion).

The possibility that the cytotoxic effect of glutamate on oligodendroglia is caused by a nonspecific mechanism related to uptake of amino acids in general was excluded by the demonstration that lysine and glycine had no cytotoxic effect in concentrations of $5 \mathrm{~mm}$ and exposure for $24 \mathrm{hr}(n=6)$ (data not shown).

Effect of inhibition of glutamate uptake on oligodendroglial toxicity. Because the data described above suggested that the oligodendroglial toxicity of glutamate required transport of glutamate into the cell, we next evaluated the effect of blockade of this transport with BHA. This compound has been shown to be a highly potent blocker of sodium-dependent, high-affinity glutamate transport (Balcar et al., 1977; Johnston et al., 1980) and probably also of sodium-independent glutamate transport (Johnston et al., 1980). Strikingly, BHA in micromolar concentrations $(45 \mu \mathrm{M})$ totally prevented the toxicity to oligodendroglia by as much as $2 \mathrm{~mm}$ glutamate (Fig. $6 \mathrm{~A}$ ). The protective effect

$\leftarrow$
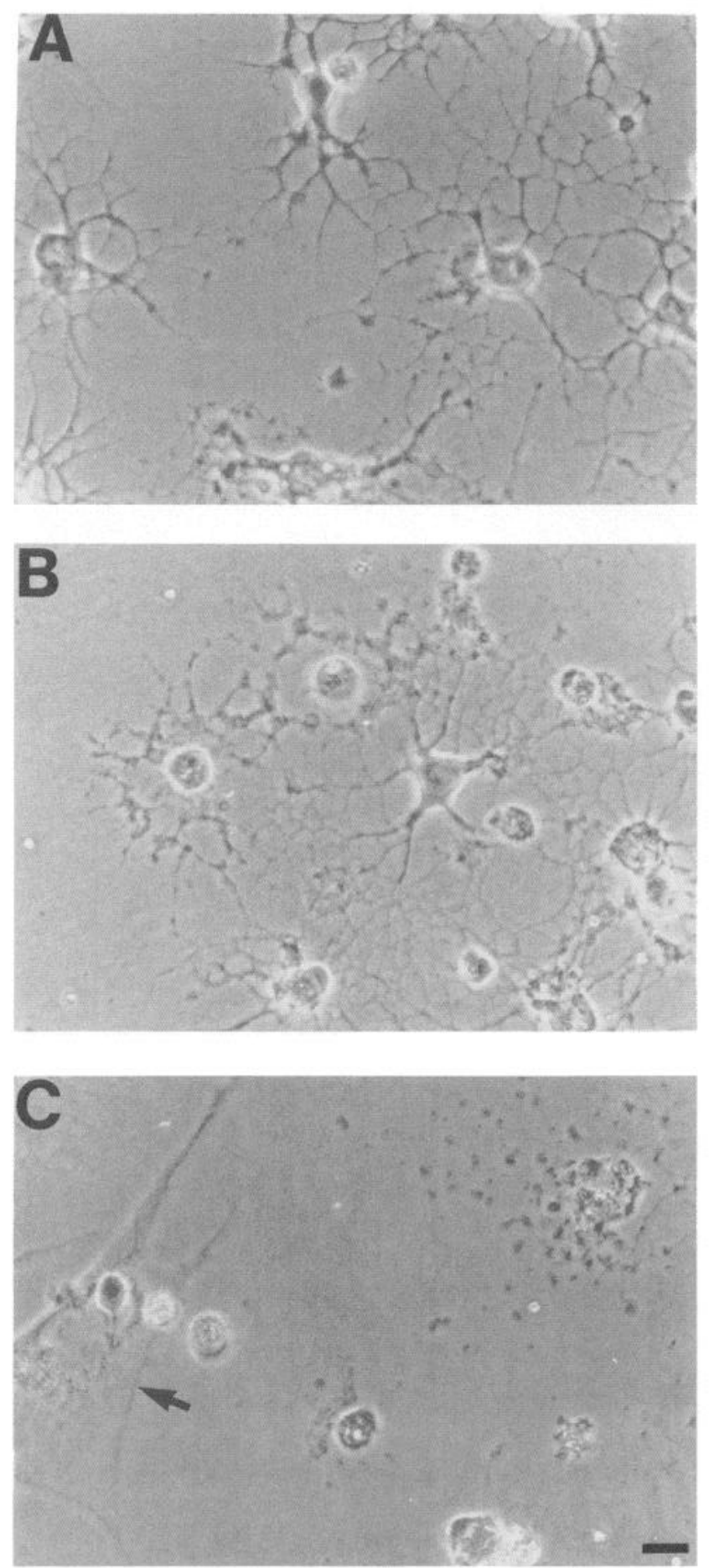

Figure 3. Phase-contrast micrographs of oligodendroglia exposed to L-glutamate. Oligodendroglia were grown for $4 \mathrm{~d}$ after separation. The medium was aspirated and replaced with EBSS. Control cultures maintained for $24 \mathrm{hr}(A)$ showed no morphological changes. In cultures exposed to $2 \mathrm{mM}$ L-glutamate in EBSS for $12 \mathrm{hr}(B)$, some cells had already undergone lysis, while others showed granular or swollen somata and processes marked with surface blebs. After $24 \mathrm{hr}$ of exposure $(C)$, almost all oligodendroglia were killed. An astrocyte (arrow) still retained intact morphology. Scale bar, $10 \mu \mathrm{m}$.

$A-D$, The phase-contrast views of 1-d-old cultures $(A, C)$ showed cells that were small and phase dark, lacking the complex network of processes. In corresponding views, most cells were A2B5 positive $(B)$ and GC negative $(D)$, indicative of presumed O2A progenitors. Less than $10 \%$ of cells were GC-positive oligodendroglia (arrow in $C$ and $D$ ). $E-H$, On the fourth day after separation, the phase-contrast views showed cells with finely branched processes $(E, G)$. At this stage, most cells expressed GC on the surface $(H)$. A cell with astrocytic morphology $(a r r o w$ in $G)$ was not stained with GC. Only a small number of A2B5-positive cells were seen at this stage (arrows in $E$ and $F$ ). Scale bar, $20 \mu \mathrm{m}$. 


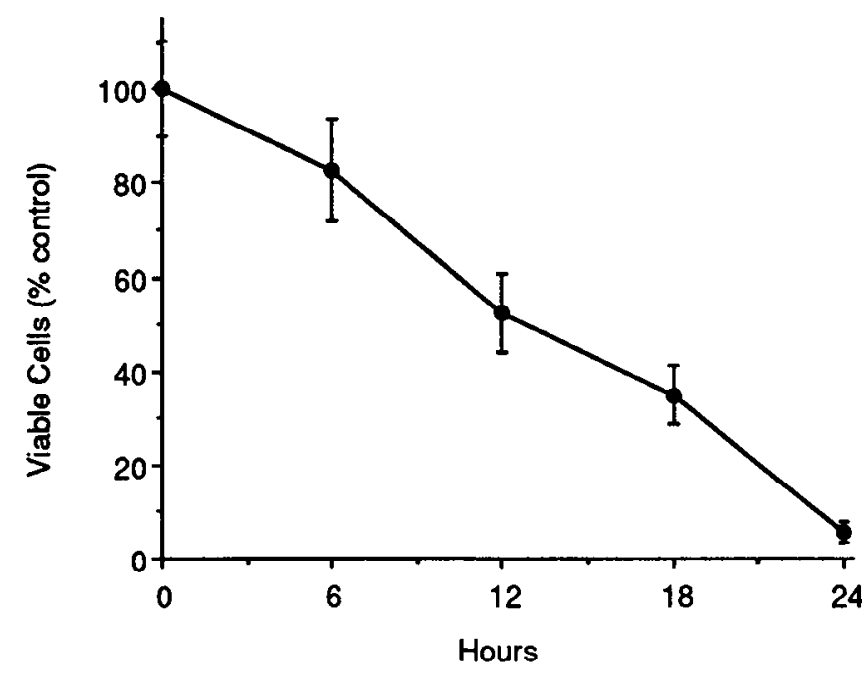

Figure 4. Time course of L-glutamate toxicity in oligodendroglia. Oligodendroglia from sister cultures were incubated with $2 \mathrm{mM}$ L-glutamate in EBSS for the indicated time. Viable cells were counted (see Materials and Methods). Data are presented as the percentage of viable cells compared to control cultures $(451$ cells). Values represent the mean \pm SD in an experiment performed in quadruplicate. Similar results were obtained in two other experiments.

of BHA was clearly dose dependent $\left(\mathrm{EC}_{50}=22 \pm 3 \mu \mathrm{M}\right.$, mean $\pm \mathrm{SEM}, n=3$ ).

In order to be sure that the effect of BHA on toxicity was due to its effect on glutamate uptake, we examincd the effect of BHA on glutamate uptake (Fig. $6 B$ ). We found that BHA inhibited

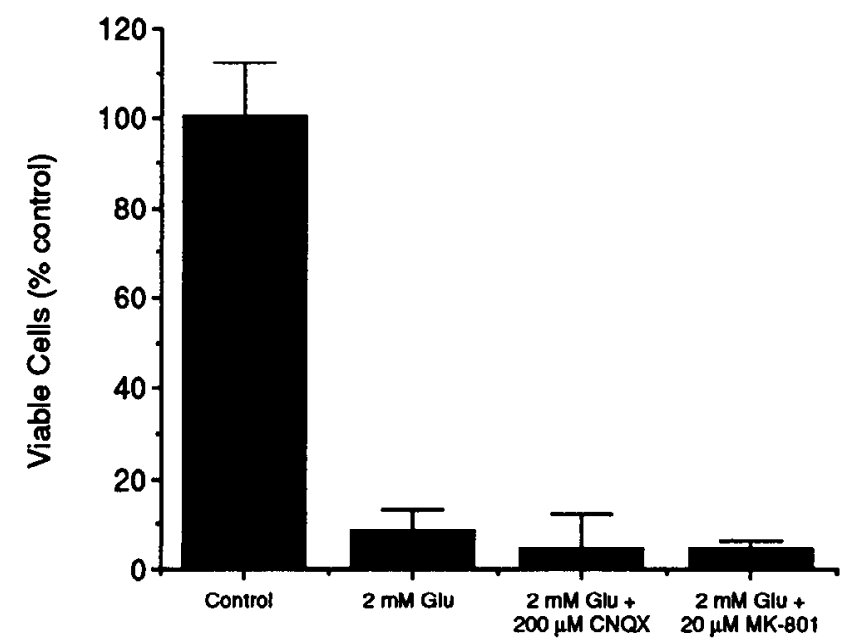

Figure 5. Failure of CNQX and MK-801 to protect oligodendroglia from L-glutamate toxicity. Oligodendroglia were incubated with $2 \mathrm{~mm}$ $\mathrm{L}$-glutamate in EBSS in the presence of $200 \mu \mathrm{M}$ CNQX or $20 \mu \mathrm{M} \mathrm{MK}$ 801 for $24 \mathrm{hr}$, and viable cells were counted. Data are presented as the percentage of viable cells compared to control cultures (691 cells). CNQX and MK-801 were not able to block L-glutamate toxicity in oligodendroglia (no significant difference compared to cultures with $2 \mathrm{~mm}$ glutamate by ANOVA). Values represent the mean \pm SD in an experiment performed in triplicate. Similar results were observed in two other experiments.

Figure 6. Glutamate transport inhibitor blocks L-glutamate toxicity in oligodendroglia. $A$, Dose-response of the protection from L-glutamate toxicity by BHA. Oligodendroglia were incubated with $2 \mathrm{~mm}$ L-gluta-
Table 1. Relative toxicity of glutamate transport substrates to oligodendroglia

\begin{tabular}{lr} 
Transport substrate & $\mathrm{EC}_{50}(\mu \mathrm{M})$ \\
\hline L-Glutamate & $197 \pm 29$ \\
D-Glutamate & $174 \pm 86$ \\
L-Aspartate & $1107 \pm 34$ \\
D-Aspartate & $24 \pm 12$
\end{tabular}

Oligodendroglia were incubated with glutamate transport substrates in EBSS for $24 \mathrm{hr}$, and viable cells were counted (see Matcrials and Mcthods). The ranges of concentrations studied were as follows: for L-glutamate, $10 \mu \mathrm{M}$ to $2 \mathrm{mM}$; D-glutamate, $10 \mu \mathrm{M}$ to $2 \mathrm{mM}$; L-aspartate, $500 \mu \mathrm{M}$ to $10 \mathrm{mM}$; and D-aspartate, $1 \mu \mathrm{M}$ to $100 \mu \mathrm{M}$. Five concentrations were studied for each range. Values represent the mean $\mathrm{EC}_{\mathrm{s}_{0}} \pm \mathrm{SEM}$ of four individual experiments performed in triplicate.

A

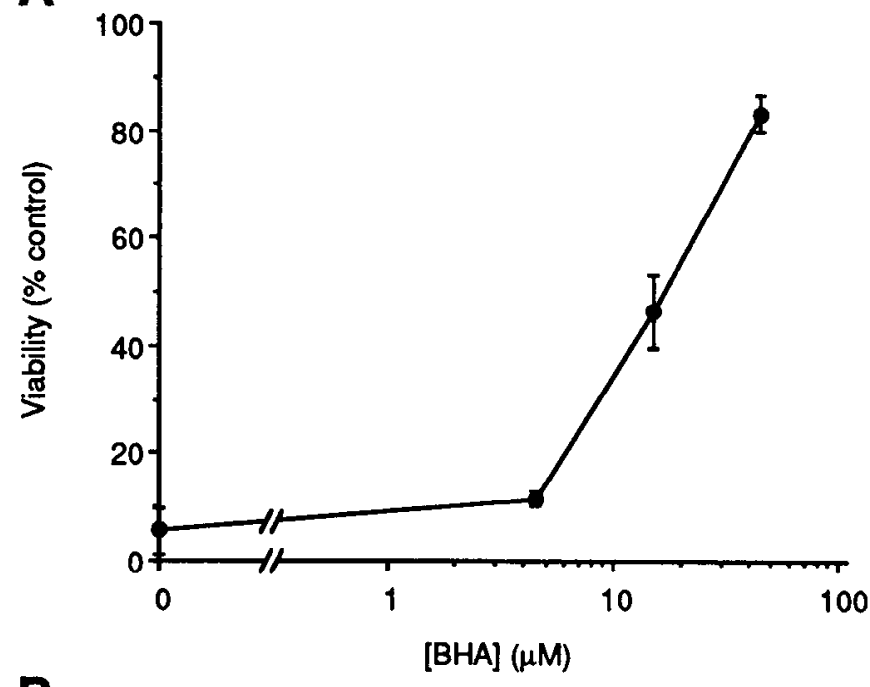

B

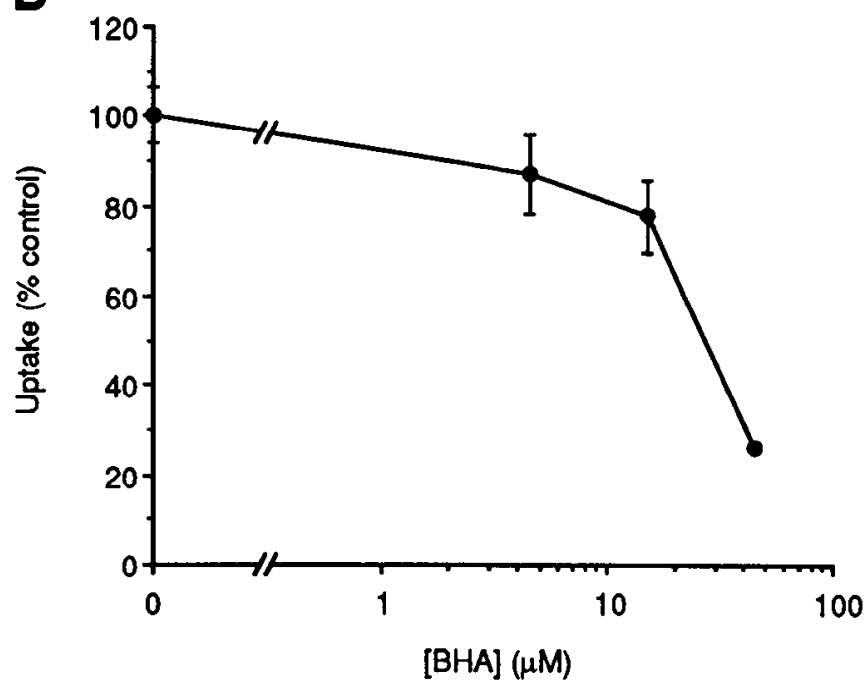

mate in EBSS in the presence of BHA for $24 \mathrm{hr}$, and viable cells were counted. Data are presented as the percentage of viable cells compared to control cultures $(416$ cells). Values represent the mean \pm SD in a single experiment performed in triplicate. The mean $\mathrm{EC}_{50} \pm \mathrm{SEM}$ in three separate experiments was $20 \pm 3 \mu \mathrm{M}$. $B$, Dose-response of inhibition of glutamate uptake by BHA. Oligodendroglia grown on 24-well plates were incubated with $1.5 \mu \mathrm{Ci}$ of $\mathrm{L}^{-3} \mathrm{H}$-glutamate $(49 \mathrm{Ci} / \mathrm{mmol})$ and $200 \mu \mathrm{M}$ nonradiolabeled L-glutamate in EBSS for $20 \mathrm{~min}$ at $37^{\circ} \mathrm{C}$ in the presence of BHA, and glutamate uptake was determined. Values represent the mean $\pm \mathrm{SD}$ in a single experiment performed in triplicate. The mean $\mathrm{EC}_{50} \pm \mathrm{SEM}$ for inhibition of glutamate uptake by $\mathrm{BHA}$ in three experiments was $18 \pm 3 \mu \mathrm{M}$. 

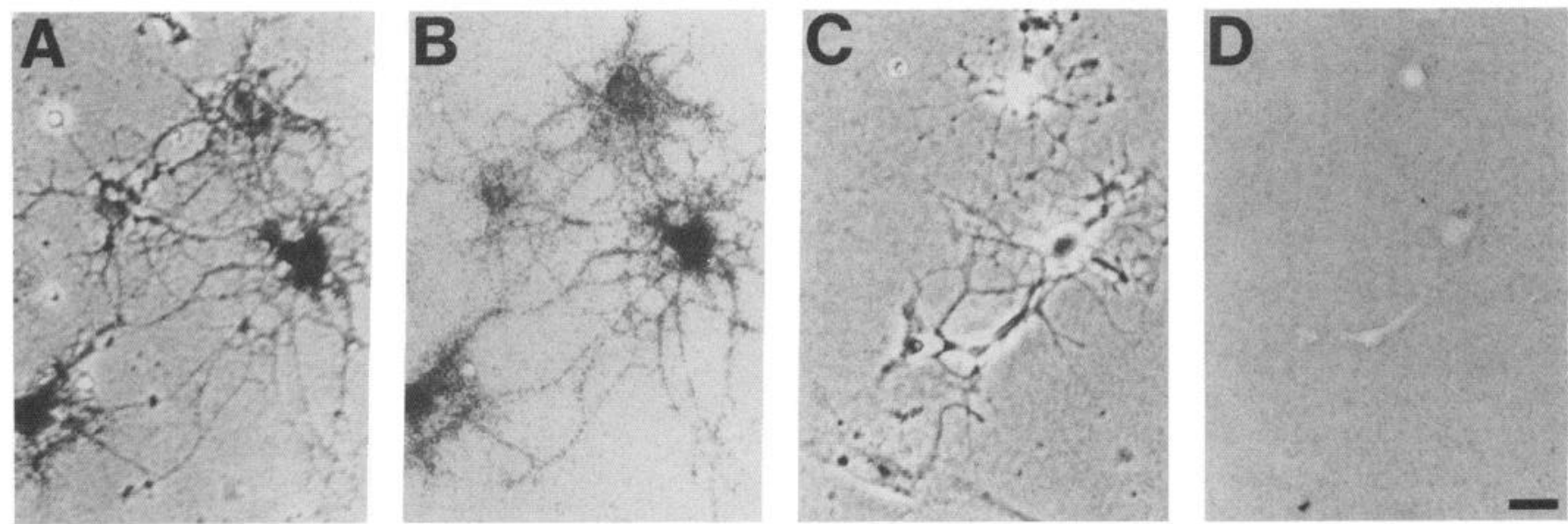

Figure 7. Glutamate uptake in oligodendroglia and the inhibition by BHA. $\mathrm{L}^{-3} \mathrm{H}$-glutamate autoradiography ( $33 \mathrm{nM} \mathrm{L-}{ }^{3} \mathrm{H}$-glutamate for $\left.5 \mathrm{~min}\right)$ was performed in oligodendroglia grown on culture slides as described in Materials and Methods. In control cells $(A$, phase contrast; $B$, bright field), processes as well as cell bodies of oligodendroglia were clearly labeled. In the presence of $45 \mu \mathrm{M}$ BHA ( $C$, phase contrast; $D$, bright field), uptake was inhibited. Scale bar, $20 \mu \mathrm{m}$.

glutamate uptake with a dose-response relationship similar to that for inhibition of glutamate toxicity. To ensure that BHA was inhibiting uptake into oligodendroglia and not just into the few contaminating astrocytes in the cultures, we studied uptake of ${ }^{3} \mathrm{H}$-glutamate by autoradiography (Fig. 7). Cell bodies and processes of control oligodendroglia were labeled clearly, but when incubated with BHA (45 $\mu \mathrm{M})$, uptake was inhibited essentially completely.

Relationship of cystine to glutamate toxicity to oligodendroglia. Coyle and colleagues have demonstrated a mechanism of glutamate-induced death in neurons that appears to be caused by glutamate inhibition of cystine uptake and that can be prevented by exogenous cystine (Murphy et al., 1989, 1990). Since the phenomenon we observed in oligodendroglia takes place in cystine-free medium, it cannot be the result of blockade of cys-

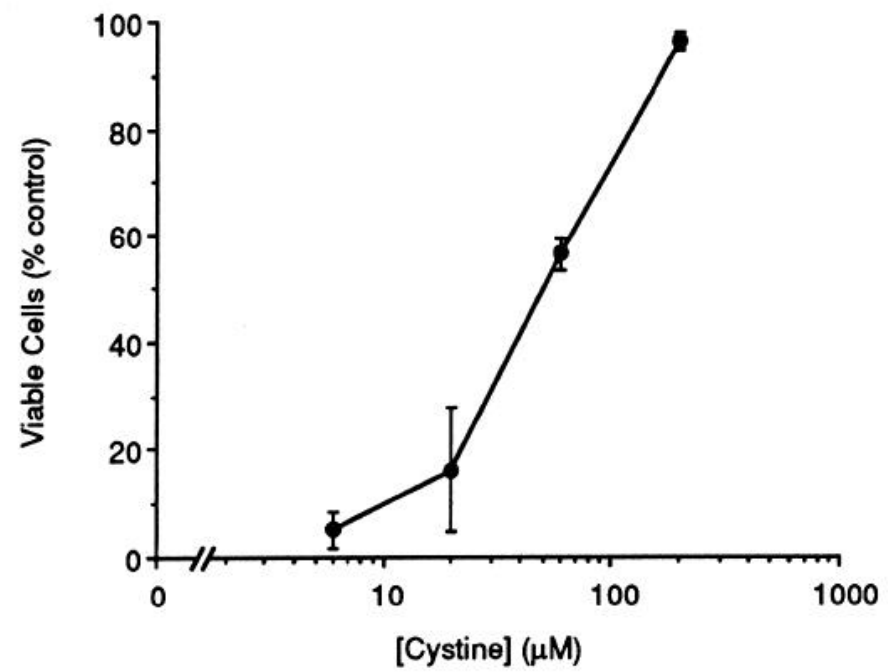

Figure 8. Dose-response of the protection from L-glutamate toxicity by cystine in oligodendroglia. Oligodendroglia were incubated with 2 mM L-glutamate in EBSS for $24 \mathrm{hr}$ in the presence of cystine, and viable cells were counted. Data are presented as the percentage of viable cells compared to control cultures (604 cells). Values represent the mean \pm $\mathrm{SD}$ in an experiment performed in triplicate. The mean $\mathrm{EC}_{50} \pm \mathrm{SEM}$ in three experiments was $52 \pm 9 \mu \mathrm{M}$. tine transport into the cells. However, since a transport system shared by glutamate and cystine that can act as an exchanger has been demonstrated in a number of extraneural cell types as well as neurons (Bannai, 1986; Kessler et al., 1987; Zaczek et al., 1987), it seemed possible that exogenous glutamate might be exchanging with endogenous cystine. Therefore, to evaluate the possibility that the oligodendroglial toxicity of glutamate may relate to a disturbance of intracellular cystine levels, we attempted to prevent the oligodendroglial toxicity of glutamate by providing the cells with exogenous cystine (Fig. 8). (As described in Materials and Methods, no cystine is present in the medium used for the toxicity studies; in the absence of glutamate, this absence of cystine has no toxic effect, as judged by the FDA method and by the lack of effect on cell growth over at least $48 \mathrm{hr}$.) Cystine ( $200 \mu \mathrm{M})$ was shown to protect oligodendroglia fully from the toxicity of glutamate present in as high

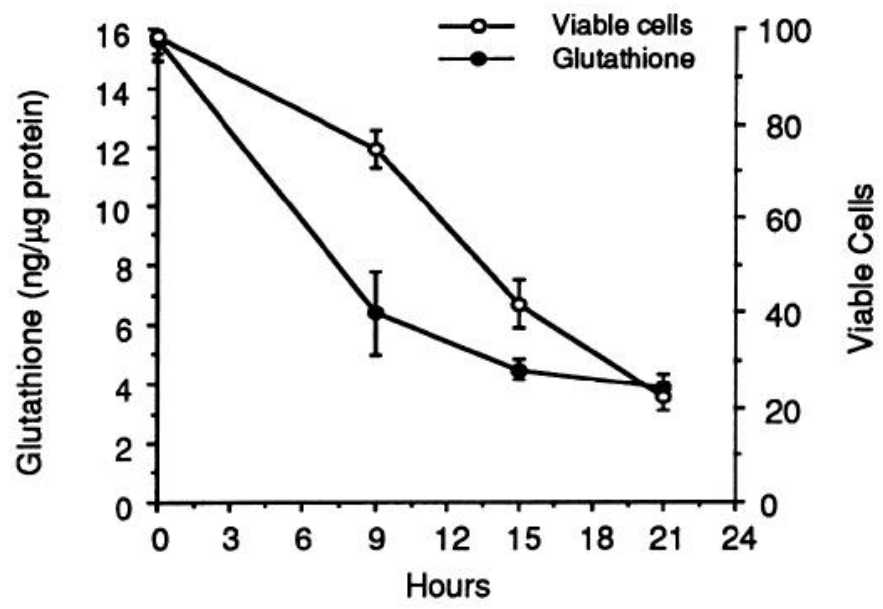

Figure 9. Glutathione levels in oligodendroglia decline prior to loss of viability in the presence of L-glutamate. Oligodendroglia from the same sister cultures were incubated with $2 \mathrm{~mm}$ L-glutamate in EBSS for the indicated times, and glutathione levels, and the number of viable cells were determined (see Materials and Methods). Data are presented as the percentage of viable cells compared to control cultures (361 cells). Values represent the mean \pm SD in an experiment performed in triplicate. Similar results were obtained in two other experiments. 


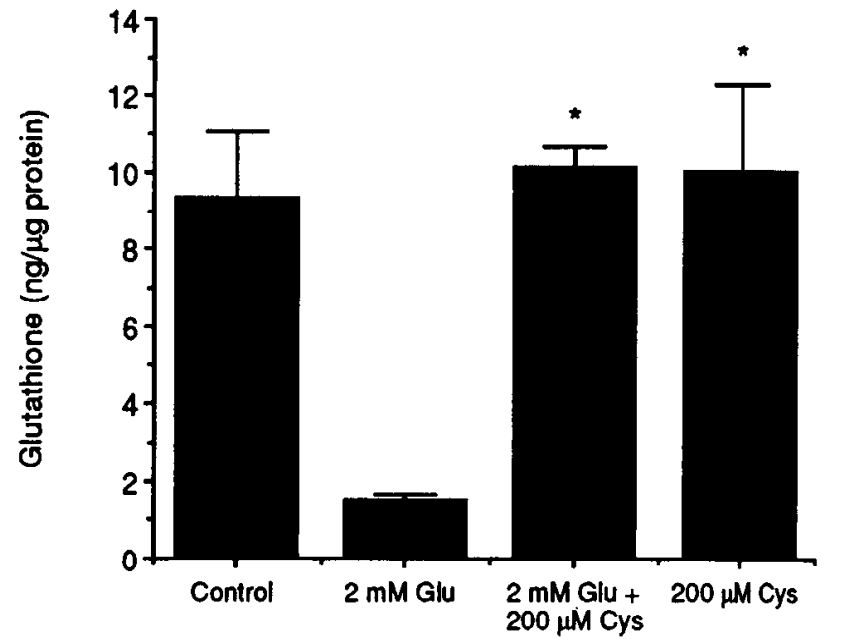

Figure 10. Prevention of glutathione depletion by cystine. Oligodendroglia were incubated with $2 \mathrm{~mm}$ L-glutamate for $21 \mathrm{hr}$ in the presence or absence of $200 \mu \mathrm{M}$ cystine in EBSS, and intracellular glutathione was determined (see Materials and Methods). Cystine (200 $\mu \mathrm{M})$ sufficient to block glutamate toxicity (Fig. 7) prevented glutathione depletion due to glutamate $\left(^{*}, p<0.001\right.$, compared to cells with $2 \mathrm{~mm}$ glutamate and no cystine by two-tailed $t$ test with Bonferroni correction). Values are the mean $\pm \mathrm{SD}$ in an experiment performed in triplicate. Similar results were obtained in two other experiments.

as a $2 \mathrm{~mm}$ concentration, and $50 \%$ protection required only approximately $50 \mu \mathrm{M}$ cystine $\left(\mathrm{EC}_{50}=52 \pm 9 \mu \mathrm{M}\right.$, mean $\pm \mathrm{SEM}$, $n-3$ ) (Fig. 8).

Protection of oligodendroglia from glutamate toxicity despite uptake of glutamate. To ensure that the protective effect of cystine was not mediated simply by prevention of glutamate uptake, similar to the action of BHA, and to determine whether protection could occur despite glutamate transport into the cell, we evaluated the effect of cystine on ${ }^{3} \mathrm{H}$-glutamate uptake in the concentrations shown to protect the cells from glutamate toxicity (i.e., $200 \mu \mathrm{M}$ cystine). Cystine had no effect on glutamate

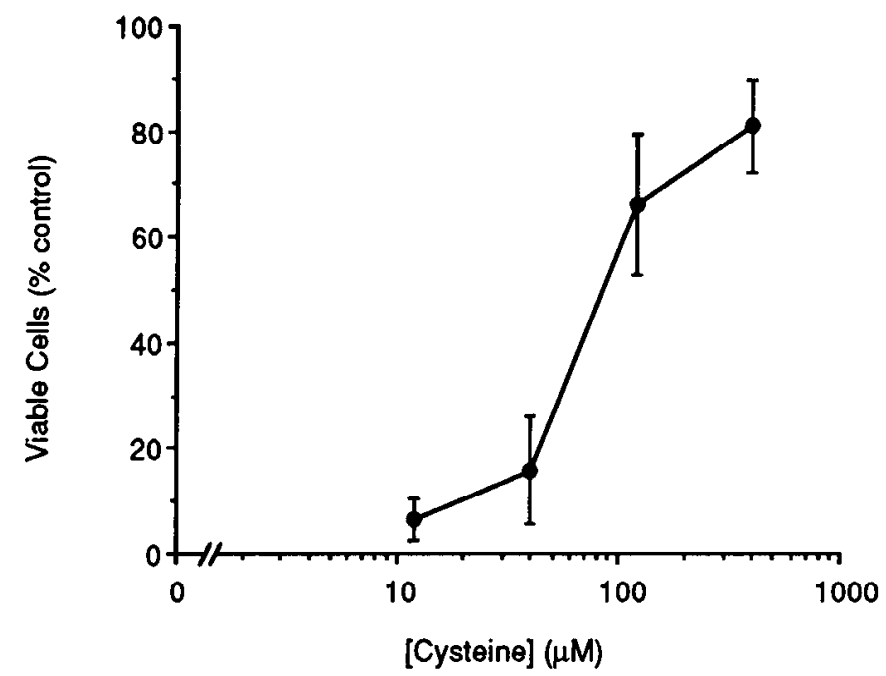

Figure 11. Dose-response of the protection from L-glutamate toxicity by cysteine in oligodendroglia. Oligodendroglia were incubated with 2 mM L-glutamate in EBSS for $24 \mathrm{hr}$ in the presence of cysteine, and viable cells were counted. Data are presented as the percentage of viable cells compared to control cultures (450-574 cells). Values represent the mean $\pm \mathrm{SD}$ of six cultures in three separate experiments. The mean $\mathrm{EC}_{50} \pm$ SEM was $99 \pm 31 \mu \mathrm{M}$.

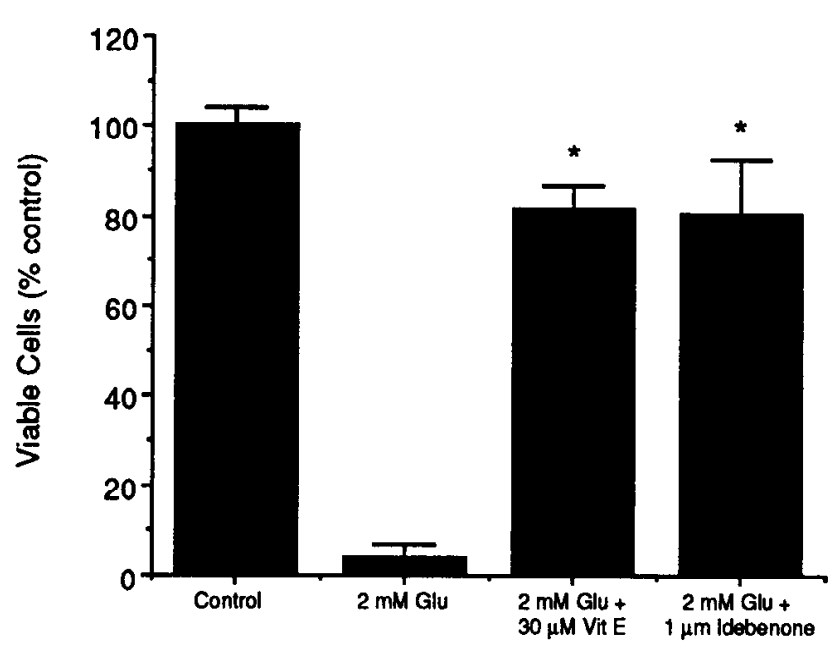

Figure 12. Protection from L-glutamate toxicity by antioxidants in oligodendroglia. Oligodendroglia were incubated with $2 \mathrm{~mm}$ L-glutamate in EBSS for $24 \mathrm{hr}$ in the presence of $30 \mu \mathrm{M}$ vitamin E or $1 \mu \mathrm{M}$ idebenone, and viable cells were counted. Data are presented as the percentage of viable cells compared to control cultures (498 cells). Vitamin E and idebenone exhibited protective effects against L-glutamate toxicity $\left(^{*}, p\right.$ $<0.001$, compared to cells exposed to L-glutamate without antioxidants by two-tailed $t$ test with Bonferroni correction). Values represent the mean $\pm S D$ in an experiment performed in triplicate. Similar results were obtained in two other experiments.

uptake at this concentration $(95 \pm 5 \%$ of control, mean \pm SEM, $n=3)$.

Role of glutathione depletion in glutamate toxicity to oligodendroglia. The above data indicate that (1) glutamate transport into the cell is critical for the oligodendroglial toxicity of this amino acid, (2) glutamate toxicity can be blocked by addition of cystine, and (3) the cystine protection occurs despite cellular uptake of glutamate. Therefore, we investigated the effect of exogenous glutamate on intracellular glutathione levels, since it has been shown that deficiency of glutathione, a metabolic product of cystine, can lead to cell death in other systems (Murphy et al., 1989, 1990; Cho and Bannai, 1990). The data show a striking decrease of glutathione levels after glutamate exposure, and the greatest decrease in glutathione levels occurred before the oligodendroglial death (Fig. 9). In parallel experiments, D-glutamate led to a decrease in glutathione levels similar to that shown in Figure 9 for L-glutamate (data not shown).

To determine whether the cystine protection of oligodendroglia from glutamate toxicity is due to prevention of the depletion of glutathione, we next determined the effect of cystine on glutathione levels (Fig. 10). Indeed, there was nearly complctc prevention of glutathione depletion at a concentration of cystine $(200 \mu \mathrm{M})$ that totally prevented the oligodendroglial toxicity of glutamate.

In further support of the conclusion that the protective effect of cystine was related causally to its prevention of glutathione depletion, we evaluated the protective effect of cysteine, the reduced form of cystine, and the form directly involved in glutathione biosynthesis (Fig. 11) (Meister and Anderson, 1983). The $\mathrm{EC}_{50}$ for protection against toxicity of $2 \mathrm{~mm}$ glutamate for $24 \mathrm{hr}$ was $99 \pm 31 \mu \mathrm{M}$ for cysteine (Fig. 11) and $52 \pm 9 \mu \mathrm{M}$ for cystine (see Fig. 8). The approximately twofold difference in $\mathrm{EC}_{50}$ is expected if cystine, as expected, is converted to cysteine (either intracellularly or extracellularly) for synthesis of glutathione. Moreover, we also showed that, as with cystine, a concentration of cysteine $(400 \mu \mathrm{M})$ sufficient to prevent the toxicity 

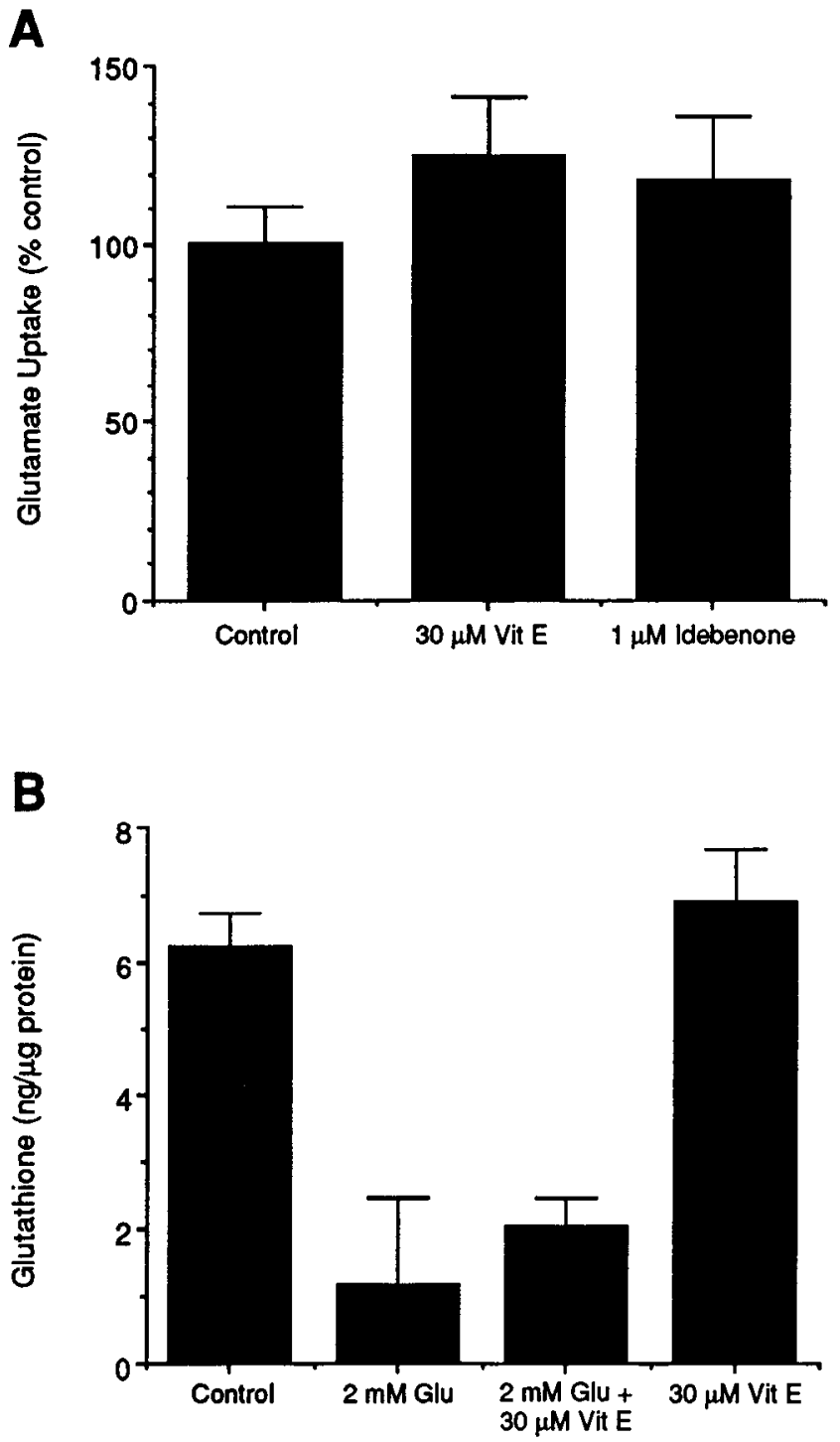

Figure 13. The effect of vitamin $\mathrm{E}$ on L-glutamate uptake and on intracellular glutathione levels. $A$, For determination of L-glutamate uptake, oligodendroglia grown on 24-well plates were incubated with $1.5 \mu \mathrm{Ci}$ of $\mathrm{L}^{3} \mathrm{H}$-glutamate $(49 \mathrm{Ci} / \mathrm{mmol})$ and $200 \mu \mathrm{M}$ nonradiolabeled L-glutamate in EBSS for $20 \mathrm{~min}$ at $37^{\circ} \mathrm{C}$ in the presence of vitamin $\mathrm{E}$ and 1 $\mu \mathrm{M}$ idebenone (see Materials and Methods). Data are presented as the percentage of uptake in cultures incubated in EBSS without antioxidants. There was no inhibition of L-glutamate uptake by vitamin $E$ and idebenone (no significant difference by ANOVA). B, Depletion of glutathione was not prevented by vitamin E. Oligodendroglia were incubated with $2 \mathrm{mM}$ L-glutamate in EBSS for $21 \mathrm{hr}$ in the presence and absence of $30 \mu \mathrm{M}$ vitamin $\mathrm{E}$, and glutathione levels were determined (see Materials and Methods). Vitamin E (30 $\mu \mathrm{M})$, which protected cells from L-glutamate toxicity, did not inhibit glutathione depletion $(p=0.342$ $>0.05$, compared to cells with $2 \mathrm{mM}$ L-glutamate by two-tailed $t$ test). Values represent the mean $\pm S D$ in an experiment performed in triplicate. Similar results were obtained in two other experiments.

of a $24 \mathrm{hr}$ exposure to $2 \mathrm{~mm}$ glutamate also preserved intracellular glutathione levels (data not shown).

Role for oxidative stress and free radicals in glutamate toxicity to oligodendroglia. Because glutathione is an important cellular protective agent against oxidative stress (for reviews, see Floyd, 1990; Bast et al., 1991; Sies, 1991; Traystman et al., 1991), we evaluated the possibility that the toxicity of glutamate to oligodendroglia involved a free radical mechanism. The effect of

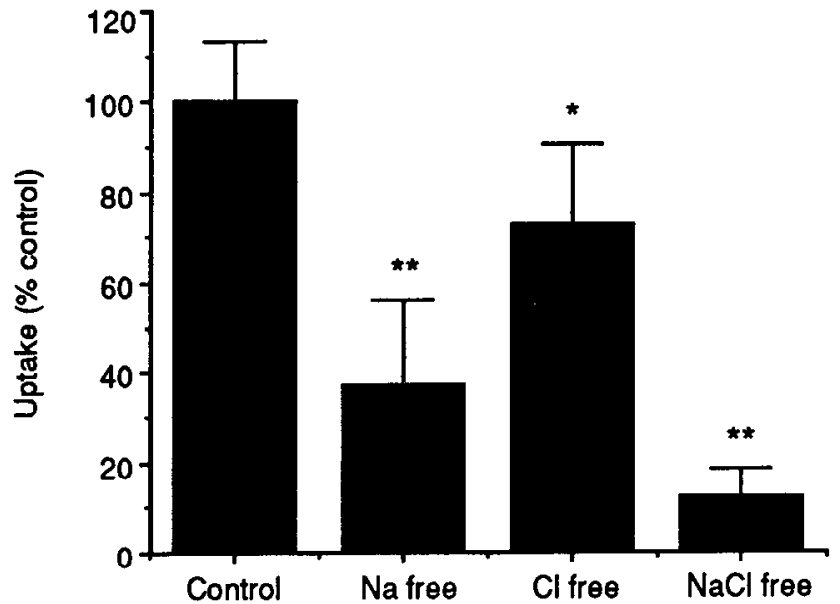

Figure 14. Glutamate uptake in $\mathrm{Na}^{+}$- and/or $\mathrm{Cl}^{-}$-free solutions. Oligodendroglia grown on 24-well plates were incubated with $1.5 \mu \mathrm{Ci}$ of $\mathrm{L}^{3} \mathrm{H}$-glutamate $(49 \mathrm{Ci} / \mathrm{mmol})$ and $200 \mu \mathrm{M}$ nonradiolabeled L-glutamate for $20 \mathrm{~min}$ at $37^{\circ} \mathrm{C}$. In control cultures, TBS consisting of $120 \mathrm{mM} \mathrm{Na}^{+}$, $5.4 \mathrm{~mm} \mathrm{~K}^{+}, 130.6 \mathrm{mM} \mathrm{Cl}^{-}, 1.8 \mathrm{~mm} \mathrm{Ca}^{2+}, 0.8 \mathrm{~mm} \mathrm{Mg}^{2+}, 16 \mathrm{~mm}$ glucose, and $25 \mathrm{~mm}$ Tris base was used. For ion deficient media, sodium and chloride in TBS were replaced in isomolar amounts by $N$-methylglucamine and sulfate, respectively. L-Glutamate uptake was determined as described in Materials and Methods. Data are presented as the percentage of uplake in cultures incubated in standard TBS. L-Glutamate uptake was inhibited in sodium- and/or chloride-free conditions $\left({ }^{* *}, p\right.$ $<0.001 ;^{*}, p<0.01$, compared to control by two-tailed $t$ test with Bonferroni correction). Values represent the mean $\pm \mathrm{SD}$ of nine cultures in three separate experiments.

the free radical scavengers, vitamin E $(30 \mu \mathrm{M})$ (Burton and Ingold, 1989; Niki et al., 1989) or idebenone (1 $\mu \mathrm{M})$ (Suno and Nagaoka, 1984), on oligodendroglial toxicity to glutamate was studied (Fig. 12). Both compounds totally protected oligodendroglia from the toxicity of as much as $2 \mathrm{~mm}$ glutamate. These data suggest that cellular depletion of glutathione leads to vulnerability to oxidative stress and free radical-mediated toxicity.

We next determined whether glutamate toxicity could be prevented by the free radical scavengers despite uptake of glutamate into the cells and despite glutathione depletion (Fig. 13). Glutamate uptake was unaffected by concentrations of vitamin $E$ and idebenone that totally protect oligodendroglia from glutamate toxicity (Fig. 13A). Moreover, vitamin E was shown to protect the cells against glutamate toxicity despite the occurrence of glutathione depletion (Fig. 13B).

Glutamate transport in oligodendroglia. Taken together, these data suggest an important role for glutamate uptake in glutamate toxicity to oligodendroglia. Because of this central role of uptake, we investigated glutamate transport further. We evaluated the ionic dependency of glutamate uptake in oligodendroglia in the absence of $\mathrm{Na}^{+}$or $\mathrm{Cl}^{-}$or both (Fig. 14), because of the reported presence in other cells of sodium-dependent (high-affinity, ouabain-sensitive) and sodium-independent, chloride-dependent transport systems. Both systems appear to be present in oligodendroglia, since the $\mathrm{Na}^{+}$-free condition results in approximately $65 \%$ inhibition of uptake, the chloride-free condition in approximately $25 \%$ inhibition; and the sodium and chloridefree condition in approximately $90 \%$ inhibition.

We next studied the kinetics of $\mathrm{L}^{-3} \mathrm{H}$-glutamate uptake (Fig. 15). The findings support the presence of two systems, and Lineweaver-Burk plots resulted in values for $K_{m}$ and $V_{\max }$ for the higher-affinity system of $3.9 \mu \mathrm{M}$ and $3.4 \mathrm{nmol} / \mathrm{min} / \mathrm{mg}$ protein, 


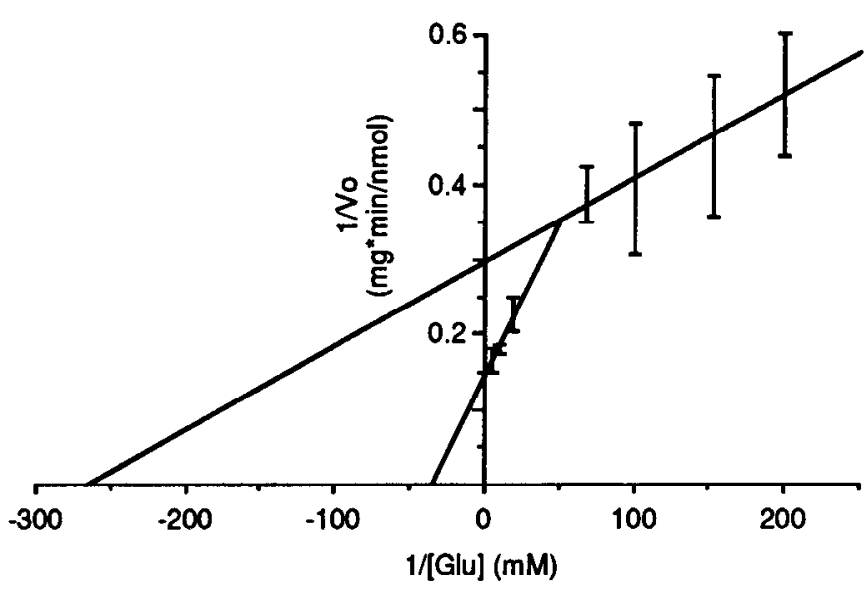

Figure 15. Kinetics of L-glutamate uptake in oligodendroglia (Lineweaver-Burk plots). Oligodendroglia grown on 24-well plates were incubated with the indicated concentrations of $\mathrm{L}$-glutamate containing $1.5-15 \mu \mathrm{Ci}$ of $\mathrm{L}^{-3} \mathrm{H}$-glutamate $(49.0 \mathrm{Ci} / \mathrm{mmol})$ in $0.3 \mathrm{ml}$ of EBSS for 2 min at $37^{\circ} \mathrm{C}$. L-Glutamate uptake was determined as described in Materials and Methods. Two uptake systems were apparent. Values of $K_{m}$ and $V_{\max }$ were, respectively, $3.9 \mu \mathrm{M}$ and $3.4 \mathrm{nmol} / \mathrm{min} / \mathrm{mg}$ protein for the higher-affinity system and $30.0 \mu \mathrm{M}$ and $7.1 \mathrm{nmol} / \mathrm{min} / \mathrm{mg}$ protein for the lower-affinity system. Values represent the mean \pm SEM in three experiments performed in duplicate.

and for the lower-affinity system, of $30.0 \mu \mathrm{M}$ and $7.1 \mathrm{nmol} / \mathrm{min} /$ mg protein. The $K_{m}$ value for the higher-affinity system in oligodendroglia is comparable to the lowest values reported for the $\mathrm{Na}^{+}$-dependent high-affinity systems in neurons and astrocytes (Nicholls and Attwell, 1990). The $K_{m}$ value for the loweraffinity system in oligodendroglia is similar to the $K_{m}$ of the glutamate-cystine transport system (see below) in C- 6 glioma cells (Cho and Bannai, 1990), which in turn may be comparable to the low-affinity transport system studied in brain slices (Benjamin and Quastel, 1976), synaptosomes (Takagaki, 1976), and glioma cells (Henn et al., 1974).

Promotion of cystine efflux by glutamate. Because the loweraffinity, glutamate-cystine transport system can act as an exchanger in neurons (Kessler et al., 1987; Zaczek et al., 1987), we evaluated the possibility that such a system was operative in oligodendroglia and that glutamate entrance into the cells promotes cystine efflux. Cells prelabeled by preincubation with ${ }^{35} \mathrm{~S}$-cystine were exposed to $2 \mathrm{~mm}$ glutamate and efflux of radioactivity determined (Fig. 16). Glutamate clearly caused efflux of $\left[{ }^{35} \mathrm{~S}\right]$ radioactivity into the medium; the rate of efflux in the glutamate-treated cultures was more than threefold higher than the rate of efflux in the control cultures. In a parallel experiment, D-glutamate led to an increase in cystine efflux similar to that shown in Figure 16 for L-glutamate. ${ }^{35} \mathrm{~S}$-Cystine was isolated by thin-layer chromatography (see Materials and Methods), and radioactivity was determined and found to be 4.9-fold higher in the glutamate-treated than in the control cultures.

\section{Discussion}

Oligodendroglia were found in this study to be highly vulnerable to glutamate-induced cell death. The $\mathrm{EC}_{50}$ for glutamate for a $24 \mathrm{hr}$ glutamate exposure was approximately $200 \mu \mathrm{M}$. Astrocytes of a comparable stage of development were found to be markedly resistant to glutamate toxicity; indeed, no toxicity to astrocytes was observed at $5 \mathrm{~mm}$ glutamate. Moreover, the $\mathrm{EC}_{50}$ for glutamate toxicity to oligodendroglia was comparable to the $\mathrm{EC}_{50}$ for neuronal toxicity caused by this amino acid in con-

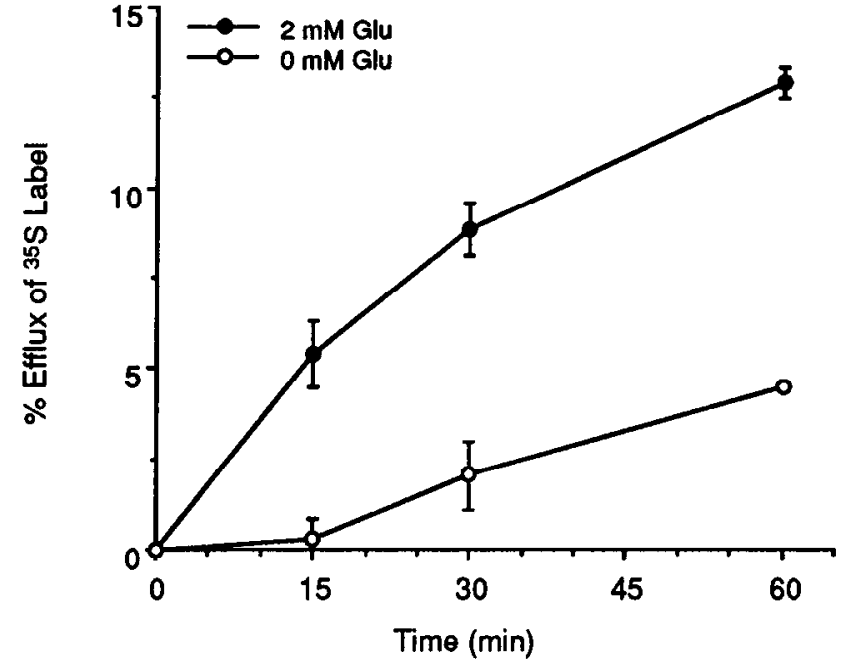

Figure 16. L-Glutamate promotes efflux of $\left.{ }^{35} \mathrm{~S}\right]$ radioactivity from oligodendroglia prelabeled with $\left.{ }^{35} \mathrm{~S}\right]$. Cells grown in $35 \mathrm{~mm}$ dishes were incubated in EBSS containing $1.5 \mu \mathrm{Ci}$ of $\mathrm{L}^{-35} \mathrm{~S}$-cystine $(405.2 \mathrm{Ci} / \mathrm{mmol})$ for $60 \mathrm{~min}$. After washing three times, cells were incubated in $1.2 \mathrm{ml}$ of EBSS with 0 or $2 \mathrm{mM} \mathrm{L}$-glutamate for the indicated times at $37^{\circ} \mathrm{C}$. After incubation, media were collected, and cells were washed once and lysed in $0.1 \mathrm{~N} \mathrm{NaOH}$. Radioactivity in media and cells were determined by liquid scintillation, and percentage efflux of ${ }^{35} S$ label was calculated as described in Materials and Methods. Values represent the mean \pm SD in an experiment performed in duplicate. Similar results were obtained in three other experiments.

ventional cerebral cortical cultures derived from mouse (Koh and Choi, 1988) or rat (Rosenberg and Aizenman, 1989; Rosenberg et al., 1992). However, the temporal characteristics of glutamate-induced oligodendroglial death are different from those for neuronal death; the former requires hours of exposure whereas the latter occurs in less than an hour. Our cultures of oligodendroglia contain fewer astrocytes, and in this respect resemble more closely the astrocyte-poor cultures described by Rosenberg and Aizenman (1989), in which it was possible to measure the intrinsic vulnerability of neurons to glutamate. In our oligodendroglia-enriched, astrocyte-poor cultures, we believe we are able to measure the intrinsic vulnerability of oligodendroglia to glutamate, and while these cells are less sensitive to glutamate than are neurons, they are markedly more vulnerable to glutamate toxicity than are astrocytes. Whether astrocytes confer on oligodendroglia a similar degree of protection from glutamate toxicity as they confer upon neurons remains an important topic for future study. In any case, the unexpected finding is that oligodendroglia, as well as neurons, are potential targets for glutamate toxicity in the developing mammalian CNS.

The inability of MK-801 or CNQX to block the toxicity of glutamate to oligodendroglia suggests that the mechanism of oligodendroglial death caused by glutamate is not mediated by excitatory amino acid receptors, in contrast to the mechanisms of glutamate neurotoxicity (Choi, 1988; Choi and Rothman, 1990; Meldrum and Garthwaite, 1990). Instead, the oligodendroglial toxicity of glutamate appears to be mediated primarily by glutamate transport mechanisms. A similar conclusion was drawn for the neuronal toxicity of glutamate and quisqualate in studies of toxicity to immature neurons (Murphy et al., 1989, 1990).

The requirement for transport of glutamate into oligodendroglia to produce cell death was shown by the total prevention of cell death by blockade by an antagonist of glutamate trans- 
port, BHA. The protective effect of BHA exhibited the same dose dependency as did its inhibitory effect on glutamate uptake. BHA has been shown to be a highly potent blocker of the sodium-dependent, high-affinity glutamate transport system described in neurons and astrocytes (Balcar et al., 1977; Johnston et al., 1980). However, that this system cannot be exclusively involved in the glutamate toxicity to oligodendroglia is demonstrated by the fact that D-glutamate, which is not transported by the sodium-dependent, high-affinity system (Benjamin and Quastel, 1976), is highly toxic. [The similar effects of D-glutamate and L-glutamate on cystine efflux and glutathione levels, however, do suggest that the mechanism of toxicity of the two stereoisomers is the same (see later discussion).] Moreover, BHA has been shown to block sodium-independent glutamate transport as well as the sodium-dependent system (Johnston et al., 1980). The only previous suggestion of a glutamate uptake system in oligodendroglia was the demonstration by autoradingraphy of the uptake of radioactive D-aspartate by oligodendroglia in mixed glial primary cultures by Reynolds and Herschkowitz (1986). However, uptake of L-glutamate could not be demonstrated in those experiments. We were able to demonstrate uptake of glutamate into oligodendroglia in our cultures by autoradiography, as well as by tracer experiments. A kinetic analysis of the ${ }^{3} \mathrm{H}$-glutamate uptake data that we obtained suggests the presence of two uptake systems in oligodendroglial cultures, with the $K_{m}$ of one nearly an order of magnitude greater than the $K_{m}$ of the other.

The present studies demonstrate in four ways that the toxicity of glutamate is mediated by depletion of intracellular cystine leading to depletion of glutathione. First, addition of cystine totally prevented the glutamatc toxicity to oligodendroglia. This striking protective effect was comparable to that shown by Coyle and coworkers with immature neurons (Murphy et al., 1989, 1990). Second, addition of cysteine, the reduced form of cystine that is involved in glutathione biosynthesis, also totally prevented the glutamate toxicity to oligodendroglia, and the $\mathrm{EC}_{50}$ for this prevention was twofold that for cystine, the disulfide derivative from which cysteine is generated. Third, glutathione levels were shown to decrease markedly in cells exposed to glutamate, and this marked decrease preceded the loss of cell viability. Fourth, glutamate toxicity could be prevented totally by simultaneous exposure to two different free radical scavengers, vitamin $\mathrm{E}$ and idebenone. This observation is consistent with the fact that glutathione, a crucial cellular product of cysteine (Murphy et al., 1989, 1990; Cho and Bannai, 1990), is an important protective agent against oxidative stress (for reviews, sec Floyd, 1990; Bast ct al., 1991; Sies, 1991; Traystman et al., 1991).

The oligodendroglial cell death caused by glutamate thus appears to involve a mechanism that ultimately renders the cell vulnerable to oxidative stress, probably because of depletion of glutathione. How could glutamate lead to this depletion? The major possibility is that oligodendroglia contain the transport system described in extraneural cells that is shared by glutamate and cystine, and that can operate as an exchange system in neurons (Kessler et al., 1987; Zaczek et al., 1987). Promotion of cystine efflux and, thereby, glutathione depletion by glutamate uptake via such an exchange system would be consistent with the prevention of both glutamate toxicity and glutathione depletion by addition of cystine or cysteine. We showed that glutamate exposure does cause efflux of ${ }^{35} \mathrm{~S}$-cystine after oligodendroglia were prelabeled with this amino acid.
These observations of differentiating oligodendroglia in culture raise the possibility that the oligodendroglial cell death associated with the periventricular leukomalacia of premature infants is caused, at least in part, by glutamate. The earliest neuropathological features of this lesion are coagulation necrosis, that is, infarction with disruption of axis cylinders (Banker and Larroche, 1962). Death of oligodendroglia, extending beyond the areas of focal necrosis, has been shown neuropathologically in the acute stage and has been deduced from the finding of subsequently impaired myelination by brain imaging as well as neuropathology (DeReuck et al., 1972; Gilles et al., 1983; DeVries et al., 1988; Dambska et al., 1989; Leviton and Paneth, 1990; Paneth et al., 1990). We hypothesize that this oligodendroglial death is caused, at least in part, by increased extracellular glutamate, released locally from injured axis cylinders, which contain millimolar concentrations of this amino acid (Battistin et al., 1971; Fonnum, 1984; Beneveniste, 1991). A similar formulation would be relevant to oligodendroglial injury in areas of cerebral infarction in older patients with stroke. In either case, the possibility is raised of novel therapies directed against glutamate transport into the oligodendroglial cell, glutathione depletion, and free radical attack.

\section{References}

Balcar VJ, Johnston GAR, Twitchin B (1977) Stereospecificity of the inhibition of L-glutamate and L-aspartate high affinity uptake in rat brain slices by threo-3-hydroxyaspartate. J Neurochem 28:1 145-1146.

Banker BQ, Larroche JC (1962) Periventricular leukomalacia of infancy. Arch Neurol 7:386-410.

Bannai S (1986) Exchange of cystine and glutamate across plasma membrane of human fibroblasts. J Biol Chem 261:2256-2263.

Bansal R, Warrington AE, Gard AL, Ranscht B, Pfeiffer SE (1989) Multiple and novel specificities of monoclonal antibodies O1, O4, and $\mathrm{R}-\mathrm{mAb}$ used in the analysis of oligodendrocyte development. J Neurosci Res 24:548-557.

Barres BA, Chun LLY, Corey DP (1988) Ion channel expression by white matter glia. I. Type 2 astrocytes and oligodendrocytes. Glia $1: 10-30$.

Barres BA, Chun LLY, Corey DP (1990) Ion channels in vertebrate glia. Annu Rev Neurosci 13:441-474.

Bast A, Haenen GR, Doelman CJ (1991) Oxidants and antioxidants: state of the art. Am J Med 91:2S-13S.

Bastmeyer M, Beckmann M, Schwab ME, Stuermer CAO (1991) Growth of regenerating goldfish axons is inhibited by rat oligodendrocytes and CNS myelin but not by goldfish optic nerve tract oligodendrocytelike cells and fish CNS myelin. J Neurosci 11:626-640.

Battistin L, Grynbaum A, Lajtha A (1971) The uptake of various amino acids by the mouse brain in vivo. Brain Res 29:85-99.

Beneveniste $H$ (1991) The excitotoxin hypothesis in relation to cerebral ischemia. Cerebrovasc Metab Rev 3:213-245.

Benjamin AM, Quastel JH (1976) Cerebral uptakes and exchange diffusion in vitro of $\mathrm{L}$ - and D-glutamates. J Neurochem 26:431-441.

Bologa-Sandru L, Siegrist HP, Z'Graggen A, Hofmann K, Wiesmann U, Dahl D, Herschkowitz N (1981) Expression of antigenic markers during the development of oligodendrocytes in mouse brain cell cultures. Brain Res 210:217-229.

Booher J, Sensenbrenner M (1972) Growth and cultivation of dissociated neurons and glial cells from embryonic chick, rat and human brain in flask cultures. Neurobiology 2:97-105.

Bradford M (1976) A rapid and sensitive method for the quantitation of microgram quantities of protein utilizing the principle of proteindye binding. Anal Biochem 72:248-254.

Bray GM, Villegas-Perez MP, Vidal-Sanz M, Carter DA, Aguayo AJ (1991) Neuronal and nonneuronal influences on retinal ganglion cell survival, axonal regrowth, and connectivity after axotomy. Ann NY Acad Sci 633:214-228.

Bunge RP (1968) Glial cells and the central myelin sheath. Physiol Rev 48:197-251.

Burton GW, Ingold KU (1989) Vitamin $\mathrm{E}$ as an in vitro and in vivo antioxidant. Ann NY Acad Sci 570:7-22. 
Cadelli DS, Bandtlow CE, Schwab ME (1992) Oligodendrocyte- and myelin-associated inhibitors of neurite outgrowth: their involvement in the lack of CNS regeneration. Exp Neurol 115:189-192.

Cho Y, Bannai S (1990) Uptake of glutamate and cystine in C-6 glioma cells and in cultured astrocytes. J Neurochem 55:2091-2097.

Choi DW (1988) Glutamate neurotoxicity and diseases of the nervous system. Neuron 1:623-634.

Choi DW, Rothman SN (1990) The role of glutamate neurotoxicity in hypoxic-ischemic neuronal death. Annu Rev Neurosci 12:171182.

Choi DW, Maulucci-Gedde M, Kriegstein AR (1987) Glutamate neurotoxicity in cortical cell culture. J Neurosci 7:357-368.

Dambska M, Laure-Kamionowska M, Schmidt-Sidor B (1989) Early and late neuropathological changes in perinatal white matter damage. J Child Neurol 4:291-298.

DeReuck J, Chattha AS, Richardson EP Jr (1972) Pathogenesis and evolution of periventricular leukomalacia in infancy. Arch Neurol 27: 229-236.

de Vellis J, Morrison RS, Peng WW, Arenander AT (1983) The use of primary glial cell cultures in developmental studies of the central nervous system. Birth Defects 19:67-78.

DeVries LS, Wigglesworth JS, Regev R, Dubowitz LMS (1988) Evaluation of periventricular leukomalacia during the neonatal period and infancy: correlation of imaging and postmortem findings. Early Hum Dev 17:205-219.

Eccleston PA, Silberberg DH (1984) The differentiation of oligodendrocytes in a serum-free hormone-supplemented medium. Dev Brain Res 16:1-9.

Flodmark O, Lupton B, Li D, Stimac GK, Roland EH, Hill A, Whitfield MF, Norman MG (1989) MR imaging of periventricular leukomalacia in childhood. Am J Roentgenol 152:583-590.

Floyd RA (1990) Role of oxygen free radicals in carcinogenesis and brain ischemia. FASEB J 4:2587-2597.

Fonnum FJ (1984) Glutamate: a neurotransmitter in mammalian brain. J Neurochem 42:1-11.

Gard AL, Pfeiffer SE (1990) Two proliferative stages of the oligodendrocyte lineage (A2B5 ${ }^{+} \mathrm{O}^{-}$and $\mathrm{O}^{+}{ }^{+} \mathrm{GalC}^{-}$) under different mitogenic control. Neuron 5:615-625.

Gilles FH, Murphy SF (1969) Perinatal telencephalic leucoencephalopathy. J Neurol Neurosurg Psychiatry 32:404-413.

Gilles FH, Leviton A, Dooling EC (1983) The developing human brain. Boston: Wright.

Giulian D, Baker TJ (1986) Characterization of ameboid microglia isolated from developing mammalian brain. J Neurosci 6:2163-2178.

Henn FA, Goldstein MN, Hamberger A (1974) Uptake of the neurotransmitter candidate glutamate by glia. Nature 249:663-664.

Hertz L, Juurlink BHJ, Fosmark H, Schousboe A (1982) Methodological appendix: astrocytes in primary cultures. In: Neuroscience approached through cell culture (Pfeiffer SE, ed), pp 175-186. Boca Raton, FL: CRC

Hertz L, Juurlink BHJ, Szuchet S (1985) Cell cultures. In: Handbook of neurochemistry (Lajtha A, ed), pp 603-661. New York: Plenum.

Honore T, Davies SN, Drejer J, Fletcher EJ, Jacobsen P, Lodge D, Neilsen FE (1988) Quinoxalinediones: potent competitive nonNMDA glutamate receptor antagonists. Science 241:701-703.

Huettner JE, Bean BP (1988) Block of $N$-methyl-D-aspartate-activated current by the anticonvulsant MK-801: selective binding to open channels. Proc Natl Acad Sci USA 85:1307-1311.

Ishii S, Volpe JJ (in press) Establishment of a culture system for the study of oligodendroglial development: complementary effects of boiled serum and astrocyte extract. Dev Neurosci, in press.

Johnston GAR, Lodge D, Bornstein JC, Curtis DR (1980) Potentiation of L-glutamate and L-aspartate cxcitation of cat spinal ncurons by the stereoisomers of threo-3-hydroxyaspartate. J Neurochem 34:241-243.

Kessler M, Baudry M, Lynch G (1987) Use of cystine to distinguish glutamate binding from glutamate sequestration. Neurosci Lett 81: 221-226.

Knapp PE (1991) Studies of glial lineage and proliferation in vitro using an early marker for committed oligodendrocytes. J Neurosci Res 30:336-345.

Koh JY, Choi DW (1988) Vulnerability of cultured cortical neurons to damage by excitotoxins: differential susceptibility of neurons containing NADPH-diaphorase. J Neurosci 8:2153-2163.

Koh JY, Choi DW (1991) Selective blockade of non-NMDA receptors does not block rapidly triggered glutamate-induced neuronal death. Brain Res 548:318-321.
Langan TJ, Volpe JJ (1986) Obligatory relationship between the sterol biosynthetic pathway and DNA synthesis and cellular proliferation in glial primary cultures. J Neurochem 46:1283-1291.

Leviton A, Gilles FH (1971) Morphologic correlates of age at death of infants with perinatal telencephalic leukoencephalopathy. Am J Pathol 65:303-309.

Leviton A, Gilles FH (1973) An epidemiologic study of pcrinatal telencephalic leucoencephalopathy in an autopsy population. J Neurol Sci 18:53-66.

Leviton A, Gilles FH (1974) Astrocytosis without globules in infant cerebral white matter. An epidemiologic study. J Neurol Sci 22:329340.

Leviton A, Gilles FH (1984) Acquired perinatal leukoencephalopathy. Ann Neurol 16:1-8.

Leviton A, Paneth N (1990) White matter damage in preterm newborns - an epidemiologic perspective. Early Hum Dev 24:1-22.

Leviton A, Gilles F, Neff R, Yaney P (1976) Multivariate analysis of risk of perinatal telencephalic leucoencephalopathy. Am J Epidemiol 104:621-626.

Lopes-Cardozo M, Sykes JE, Van der Pal RH, van Golde LM (1989) Development of oligodendrocytes. Studies of rat glial cells cultured in chemically-defined medium. J Dev Physiol 12:117-127.

Lowry OH, Rosebrough NJ, Farr AL, Randall RJ (1951) Protein measurement with the Folin phenol reagent. J Biol Chem 193:265275.

Manthorpe M, Adler R, Varon S (1979) Development, reactivity, and GFA immunofluorescence of astroglia-containing monolayer cultures from rat cerebrum. J Neurocytol 8:605-621.

McCarthy KD, de Vellis J (1980) Preparation of separate astroglial and oligodendroglial cell cultures from rat cerebral tissue. J Cell Biol 85:890-902.

McDonald JW, Johnston MV (1990) Physiological and pathophysiological roles of excitatory amino acids during central nervous system development. Brain Res Rev 15:41-70.

McMorris F $\Lambda$, Dubois-Dalcq M (1988) Insulin-like growth factor I promotes cell proliferation and oligodendroglial commitment in rat glial progenitor cells developing in vitro. J Neurosci Res 21:199-209.

Meister A, Anderson ME (1983) Glutathione. Annu Rev Biochem 52: 711-760.

Meldrum B, Garthwaite J (1990) Excitatory amino acid neurotoxicity and neurodegenerative disease. Trends Pharmacol Sci 11:379-387.

Mounen G, Cam Y, Sensenbrenner M, Mandel P (1975) Variability of the effects of serum-free medium, dibutyryl cyclic AMP or theophylline on the morphology of cultured newborn rat astroblasts. Cell Tissue Res 163:365-372.

Murphy TH, Miyamoto M, Sastre A, Schnaar RL, Coyle JT (1989) Glutamate toxicity in a neuronal cell line involves inhibition of cystine transport leading to oxidative stress. Neuron 2:1547-1558.

Murphy TH, Schnaar RL, Coyle JT (1990) Immature cortical neurons are uniquely sensitive to glutamate toxicity by inhibition of cystine uptake. FASEB J 4:1624-1633.

Nicholls D, Attwell D (1990) The release and uptake of excitatory amino acids. Trends Pharmacol Sci 11:462-468.

Niki E, Yamamoto Y, Takahashi M, Komuro E, Miyama Y (1989) Inhibition of oxidation of biomembranes by tocopherol. Ann NY Acad Sci 570:23-31.

Paneth N, Rudelli R, Monte W, Rodriguez E, Pinto J, Kairam R, Kazam E (1990) White matter necrosis in very low birth weight infants: neuropathologic and ultrasonographic findings in infants surviving six days or longer. J Pediatr 116:975-984.

Persidsky MD, Baillie GS (1977) Fluorometric test of cell membrane integrity. Cryobiology 14:322-331.

Raff M, Fields K, Hakomori S, Mirsky R, Pruss R, Winter J (1979) Cell-type-specific markers for distinguishing and studying neurones and the major classes of glial cells in culture. Brain Res 174:283-308.

Raff MC, Miller RH, Noble M (1983) A glial progenitor cell that develops in vitro into an astrocyte or an oligodendrocyte depending on culture medium. Nature 303:389-396.

Reynolds R, Herschkowitz N (1986) Selective uptake of neuroactive amino acids by both oligodendrocytes and astrocytes in primary dissociated culture: a possible role for oligodendrocytes in neurotransmitter metabolism. Brain Res 371:253-266.

Rice JE III, Vannucci RC, Brierley JB (1981) The influence of immaturity on hypoxic-ischemic brain damage in the rat. Ann Neurol 9:131-141.

Rosenberg PA, Aizenman E (1989) Hundred-fold increase in neuronal 
vulnerability to glutamate toxicity in astrocyte-poor cultures of rat cerebral cortex. Neurosci Lett 103:162-168.

Rosenberg PA, Amin S, Leitner M (1992) Glutamate uptake disguises neurotoxic potency of glutamate agonists in cerebral cortex in dissociated cell culture. J Neurosci 12:56-61.

Schwab ME, Schnell L (1991) Channeling of developing rat corticospinal tract axons by myelin-associated neurite growth inhibitors. $\mathbf{J}$ Neurosci 11:709-721.

Sensenbrenner M, Labourdette G, Delaunoy JP (1980) Morphological and biochemical differentiation of glial cells in primary culture. In: Tissue culture in neurobiology (Giacobini E, Vernadakis A, Shahar A, eds), pp 385-395. New York: Raven.

Sies H (1991) Oxidative stress: from basic research to clinical application. Am J Med 91:31S-38S.

States B, Segal S (1969) Thin-layer chromatographic separation of cystine and the $N$-ethylmaleimide adducts of cysteine and glutathionen. Anal Biochem 27:323-329.

Suno M, Nagaoka A (1984) Inhibition of lipid peroxidation by a novel compound (CV-2619) in brain mitochondria and mode of action of the inhibition. Biochem Biophys Res Commun 125:1046-1052.

Takagaki G (1976) Properties of the uptake and release of glutamic acid by synaptosomes from rat cerebral cortex. J Neurochem 27: $1417-1425$
Traystman RJ, Kirsch JR, Koehler RC (1991) Oxygen radical mechanisms of brain injury following ischemia and reperfusion. Am $J$ Physiol 71:1185-1195.

van de Bor M, Guit GL, Schreuder AM, Wondergem J, Vielvoye GJ (1989) Early detection of delayed myelination in preterm infants. Pediatrics 84:407-411.

Volpe JJ (1987) Neurology of the newborn. Philadelphia: Saunders.

Volpe JJ (1989) Edward B. Neuhauser lecture. Current concepts of brain injury in the premature infant. Am J Roentgenol 153:243-251.

Watkins JC, Krogsgaard-Larsen P, Honore T (1990) Structure-activity relationships in the development of excitatory amino acid receptor agonists and competitive antagonists. Trends Pharmacol Sci 11:2533.

Waxman SG (1982) Membranes, myelin, and the pathophysiology of multiple sclerosis. New Engl J Med 306:1529-1533.

Wong EHF, Kemp JA, Priestley T, Knight AR, Woodruff GN, Iversen LL (1986) The anticonvulsant MK-801 is a potent $N$-methyl-Daspartate antagonist. Proc Natl Acad Sci USA 83:7104-7108.

Zaczek R, Balm M, Arlis S, Drucker H, Coyle JT (1987) Quisqualatesensitive, chloride-dependent transport of glutamate into rat brain synaptosomes. J Neurosci Res 18:425-431. 